Published in final edited form as:

Front Biol (Beijing). 2015 June ; 10(3): 203-220. doi:10.1007/s11515-015-1343-5.

\title{
Regulation of Hedgehog signaling by ubiquitination
}

\author{
Elaine Y. C. Hsia, Yirui Gui, and Xiaoyan Zheng* \\ Department of Anatomy and Regenerative Biology, George Washington University School of \\ Medicine and Health Sciences, Washington, DC 20037, USA
}

\begin{abstract}
The Hedgehog (Hh) signaling pathway plays crucial roles both in embryonic development and in adult stem cell function. The timing, duration and location of $\mathrm{Hh}$ signaling activity need to be tightly controlled. Abnormalities of Hh signal transduction lead to birth defects or malignant tumors. Recent data point to ubiquitination-related posttranslational modifications of several key Hh pathway components as an important mechanism of regulation of the Hh pathway. Here we review how ubiquitination regulates the localization, stability and activity of the key Hh signaling components.
\end{abstract}

\section{Keywords}

Hedgehog signaling; ubiquitination

\section{The Hh signaling pathway}

Hh proteins are cell-to-cell signals best known for their roles in embryonic tissue patterning and cell differentiation (Ingham et al. 2011; Briscoe and Therond 2013). The Hh gene is involved in embryonic segment polarity and patterning of the imaginal discs in Drosophila, and in patterning of the limb and neural tube in vertebrates (Huangfu and Anderson 2006). $\mathrm{Hh}$ signaling also has post-embryonic roles in tissue repair and regeneration, and in the maintenance of neural, hematopoietic, skin, prostate, and bladder stem cells (Jiang and Hui 2008; Petrova and Joyner 2014). Furthermore, Hh pathway activation has pathological roles in the growth of numerous cancers (Taipale and Beachy 2001; Beachy et al. 2004; Teglund and Toftgard 2010), while disruption of the pathway is linked to congenital malformations (Nieuwenhuis and Hui 2005).

Mature Hh ligand activates the pathway by binding to its receptor Patched (hereafter referred to as Ptc; dPtc in Drosophila, Ptch in vertebrates), a member of the ResistanceNodulation-Division (RND) family of proton-driven transmembrane transporters (Beachy et al. 2010), and the obligate Ptc co-receptors (Ihog and Boi in Drosophila, Cdo and Boc in vertebrates) (McLellan et al. 2006; Okada et al. 2006; Tenzen et al. 2006; Yao et al. 2006; Zhang et al. 2006b; Zheng et al. 2010; Allen et al. 2011; Izzi et al. 2011). Hh binding relieves Ptc suppression of the G-protein-coupled-receptor-like protein Smoothened (hereafter referred to as Smo; dSmo in Drosophila; vSmo in vertebrates), which in turn leads 
to a block of repressor formation and activation of the full-length $\mathrm{Ci}$ (in Drosophila) or Gli (in vertebrates) transcription factors, ultimately resulting in the expression of tissue specific target genes (Lum and Beachy 2004; Varjosalo and Taipale 2008). The primary cilium, a microtubule-based organelle that protrudes from the surface of most vertebrate cells, is a requisite hub to transduce the Hh signal in vertebrates (Goetz and Anderson 2010). In Hh's absence, the Ptch1 receptor localizes to the primary cilium, where it inhibits Smo activation and prevents Smo accumulation to the cilia. In the presence of the Hh ligand, Ptch1 disappears from the cilium, and both vSmo and the three Gli proteins accumulate in the cilium (Corbit et al. 2005; Haycraft et al. 2005; Rohatgi et al. 2007; Kim et al. 2009; Wen et al. 2010). Suppressor of Fused (Sufu), an important regulator of Gli proteins, also localizes to the cilium where it may be inhibited by activated vSmo (Haycraft et al. 2005;

Tukachinsky et al. 2010). Although most of the Drosophila cells have no primary cilium, Hh ligand also induces opposite subcellular localization changes of dPtc and dSmo: dPtc internalizes from and dSmo accumulates at the plasma membrane upon Hh stimulation (Denef et al. 2000; Zhu et al. 2003). This reciprocal change in subcellular localization mirrors that seen in vertebrate cilium, where Ptch1 exits and vSmo enters the cilium in response to Hh ligand.

Notable divergences in the Hh signaling pathway components are observed between Drosophila and vertebrates. Aside from the function of primary cilium, the most obvious difference is the presence of multiple versus singular homologs of Hh ligand, Ptc, and Gli in vertebrates. In mammals, Shh (Sonic Hedgehog) and Ihh (Indian Hedgehog) have critical functions in embryonic development, and Dhh (Desert Hedgehog) is involved in spermatogenesis (Bitgood et al. 1996; Chiang et al. 1996; St-Jacques et al. 1999; Zhang et al. 2001). Of the two vertebrate Ptch homologs, Ptch1 appears to play a major role in embryonic development, while Ptch2 has a relatively minor role (Goodrich et al. 1997; Wolff et al. 2003; Koudjis et al. 2005; Nieuwenhuis et al. 2006). There are three Gli proteins (Gli1, Gli2 and Gli3) in mammals and each contains a carboxy-terminal activation domain, but only Gli2 and Gli3 have N-terminal repressor domains (Dai et al. 1999; Sasaki et al. 1999). In the absence of $\mathrm{Hh}, \mathrm{Ci}$ and Gli2/3 are proteolytically processed into the repressor forms by removal of the carboxy-terminal activation domains, whereas the presence of $\mathrm{Hh}$ promotes formation of the full-length Ci/Gli activator forms (Aza-Blanc et al. 1997; Ohlmeyer and Kalderon 1998; Methot and Basler 1999; Aza-Blanc et al. 2000; Wang et al. 2000a). Gli1 is dispensable for development and acts to amplify the transcriptional output of Hh signaling (Park et al. 2000; Bai et al. 2002). Gli3 appears to act as the major repressor and Gli2 as the major activator of Hh signaling. (Ding et al. 1998; Matise et al. 1998; Persson et al. 2002). However, Gli2 and Gli3 have been found to share overlapping activator and repressor functions in $\mathrm{Gli}^{-/-} \mathrm{Gli3}^{-/-}$double knockout mice (Buttitta et al. 2003; Motoyama et al. 2003; Bai et al. 2004; McDermott et al. 2005).

Smo and Sufu exist as single genes in both Drosophila and vertebrates, but important divergences that affect their regulation and function in the Hh signaling pathway are also observed. Intracellular trafficking of Smo proteins is likely an important step of Hh signal transduction. Plasma membrane accumulation of dSmo is coupled with its activation (Denef et al. 2000; Zhu et al. 2003; Nakano et al. 2004), while ciliary localization of vSmo is 
necessary but not sufficient for its activation in vertebrates (Rohatgi et al. 2009; Wang et al. 2009; Wilson et al. 2009). Phosphorylation of the carboxy-terminal tail (C-tail) of dSmo and vSmo leads to their active conformation and cell surface or ciliary accumulation (Jia et al. 2004; Zhang et al. 2004; Apionishev et al. 2005; Zhao et al. 2007; Chen et al. 2011a). Nonetheless, the C-tail is the least conserved region of the Smo protein, indicating that dSmo and vSmo are regulated differently (Huangfu and Anderson 2006). In both vertebrates and invertebrates, Sufu functions downstream of Smo to antagonize Ci/Gli by binding and sequestering the transcription factors in the cytosol (Monnier et al. 1998; Ohlmeyer and Kalderon 1998; Ding et al. 1999; Kogerman et al. 1999; Methot and Basler 2000). In addition, it has been reported that mammalian Sufu directly modulates the transcriptional activity of Gli in the nucleus through recruitment of a corepressor complex (Cheng and Bishop 2002; Paces-Fessy et al. 2004). The absence of Sufu results in constitutive Hh pathway activation similar to loss of Ptch1 in mouse but has no effect in Drosophila (Preat 1992; Cooper et al. 2005; Svard et al. 2006). The differences in these phenotypes indicate that Sufu is the major inhibitor of Gli activity in mammals downstream of Ptch1, while multiple inhibitory mechanisms exist in flies (Jiang and Hui 2008).

\section{Dynamic regulation of Hh signaling}

The diverse cellular responses to Hh in different tissues during development reflect the presence of complex mechanisms that dynamically regulate the Hh signaling. As a morphogen, the secreted Hh protein forms a concentration gradient in various developing structures, such as the Drosophila wing disc or vertebrate neural tube, to control cellular differentiation and tissue patterning (Jiang and Hui 2008; Briscoe and Therond 2013). The role of $\mathrm{Hh}$ as morphogen and the molecular details on formation of the Hh concentration gradient are described in other reviews (Torroja et al. 2005; McGlinn and Tabin 2006; Guerrero and Chiang 2007; Gradilla and Guerrero 2013). One well-established feedback mechanism that serves to shape this concentration gradient involves limiting the range of the Hh signal through the conserved upregulation of Ptc (Capdevila et al. 1994a; Tabata and Kornberg 1994; Ingham and Fietz 1995; Goodrich et al. 1996; Marigo et al. 1996).

Furthermore, graded activation of downstream intracellular Hh pathway components is another way to fine-tune the interpretation of the Hh concentration gradient. For example, progressive phosphorylation of Smo at multiple sites in response to increasing Hh level is correlated with its activation along with the associated changes in conformation and subcellular localization (Jia et al. 2004; Zhao et al. 2007; Chen et al. 2011a; Fan et al. 2012). The repressor and activator forms of $\mathrm{Ci}$ regulate the expression of distinct subsets of $\mathrm{Hh}$ target genes (Methot and Basler 1999). In the Drosophila wing imaginal disc, absence of $\mathrm{Hh}$ signaling promotes $\mathrm{Ci}$ processing to the repressor form and presence of Hh signaling stimulates formation of the activator form, resulting in spatial variation in target gene expression (Methot and Basler 1999). In the vertebrate neural tube and limbs, the graded $\mathrm{Hh}$ signal may translate into a Gli activity gradient through processing of Gli3 to the repressor form (Wang et al. 2000a; Stamataki et al. 2005). The duration of exposure to Hh can also influence the cellular response, e.g., a longer exposure time to Hh ligand is necessary for high levels of Hh signaling in the neural tube (Harfe et al. 2004; Stamataki et al. 2005; Dessaud et al. 2007; Scherz et al. 2007). Thus, both positive and negative regulation of 
various Hh pathway components can be influenced by the strength and duration of the $\mathrm{Hh}$ signal.

Finally, termination of $\mathrm{Hh}$ signaling is also important for controlling the duration of pathway activity. Hh induced ubiquitination and degradation of $\mathrm{Ci} / \mathrm{Gli}$ is the most well-established mechanism for limiting signal duration, and inhibiting this process can lead to cell patterning disruption and excessive cell proliferation (Di Marcotullio et al. 2006; Huntzicker et al. 2006; Kent et al. 2006; Zhang et al. 2006a; Di Marcotullio et al. 2007; Ou et al. 2007). In addition to $\mathrm{Ci} / \mathrm{Gli}$, a growing body of evidence suggests that ubiquitination also plays critical roles in regulating other Hh signaling components including Ptc, Smo, and Sufu. Thus, ubiquitination serves as a general mechanism in the dynamic regulation of the $\mathrm{Hh}$ pathway.

\section{Protein ubiquitination}

Ubiquitination is a posttranslational modification that plays fundamental roles in diverse cellular processes including signal transduction, cell cycle progression and immune responses (Hershko and Ciechanover 1998; Voges et al. 1999). This process involves the linkage between the carboxy-terminal glycine (Gly76) of the 76-amino acid protein Ubiquitin (Ub) and the $\varepsilon$-amino group of the lysine residues on the substrate (Pickart 2001). Ubiquitination is initiated by ATP-dependent formation of a covalent bond between the $\mathrm{Ub}$ molecule and the ubiquitin-activating enzyme (E1), which activates Ub and transfers it onto ubiquitin-conjugating enzyme (E2) (Deshaies 1999). Finally, ubiquitin targets the substrate proteins either through the covalent attachment to the acceptor lysine residues by itself or with the assistance of an ubiquitin ligase (E3) (Verma and Deshaies 2000). E3s bind directly to target proteins and transfer the activated ubiquitin from the $\mathrm{E} 2$ to the lysine residues in the substrate (Baumeister et al. 1998; Pickart 2004; Pickart and Eddins 2004). To date, around one thousand E3 ligases have been identified which are classified into two families based on the presence of either a HECT (homologous to E6-AP carboxy-terminus) or a cysteine-rich RING (really interesting new gene) finger domain (Jackson et al. 2000; Pickart and Eddins 2004). HECT domain E3 ligases first attach the ubiquitin from the E2 to themselves and then transfer it to the selected substrate, while RING finger domain E3 ligases recruit the E2 and then facilitate the ubiquitin transfer (Weissman 2001).

Ub contains seven lysine (K) residues in positions K6, K11, K27, K31, K33, K48 and K63, all of which can be used as iso-peptide linkage of another Ub molecule leading to the generation of different types of ubiquitin chain conformations which can have different consequences (Woelk et al. 2007). Attachment of the first Ub on the lysine residue of the substrate results in the structural modification of $\mathrm{Ub}$, leading to the formation of the $\mathrm{Ub}$ chains. Ubiquitinated proteins may be dedicated to different fates depending on the length or linkage of the ubiquitin molecules (Lee and Tyers 2001). Monoubiquitination refers to the attachment of a single $\mathrm{Ub}$ to a single Lys residue, multi-monoubiquitination results from the attachment of single Ub molecules to several Lys residues, and polyubiquitination results from the attachment of a chain of Ub molecules to one or more Lys residues (Haglund and Dikic 2005). Polyubiquitination through K48 represents a signal for degradation of modified substrates via the $26 \mathrm{~S}$ proteasome, the best studied and canonical function of protein 
ubiquitination (Finley 2009). Polyubiquitination through K63 has been linked to various functional outcomes including lysosomal degradation and proteasome-independent mechanisms of signaling pathway activation (Chen 2012; Oshiumi et al. 2012). On the other hand, monoubiquitination through K63 is primarily associated with non-proteolytic events such as membrane trafficking, signal transduction pathways and DNA repair (Sigismund et al. 2004). The functions of unconventional ubiquitin linkages at Lys residues other than K48 and $\mathrm{K} 63$ are not well understood; however they have been found to be abundant in vivo and to be critical for degradation of protein substrates through the Ub-proteasome system (Xu et al. 2009; Chen 2012; Oshiumi et al. 2012).

It has been recently reported that ubiquitination of several key Hh pathway components represent an important mechanism for regulation of the Hh pathway. Here, we review how ubiquitination regulates the localization, stability and activity of the key Hh signaling components Ptc, Smo, Sufu, and Ci/Gli. We will also briefly discuss the physiological significance of their ubiquitination in the context of $\mathrm{Hh}$ signaling related developmental processes and disease.

\section{Regulation of Hh receptor Ptc through ubiquitination}

The Hh receptor Ptc acts to suppress the downstream pathway in the absence of Hh ligand (Rohatgi and Scott 2007). The repression of Smo by Ptc is alleviated upon Hh binding to Ptc and its co-receptors, leading to activation of the Hh signaling cascade (Beachy et al. 2010). The mechanism by which Hh regulates Ptc is unclear, although changes in Ptc protein level and subcellular distribution were found to correlate with Hh pathway activation. The Ptc gene itself is transcriptionally induced by the Hh signal (Capdevila et al. 1994a; Tabata and Kornberg 1994; Ingham and Fietz 1995; Goodrich et al. 1996; Marigo et al. 1996), and the resulting increase in Ptc protein level functions in a negative feedback manner with other Hh-binding proteins to sequester the ligand and effectively limit the range of Hh activity in vivo (Chen and Struhl 1996; Briscoe et al. 2001; Jeong and McMahon 2005; Dessaud et al. 2007; Zheng et al. 2010). Furthermore, observations that dPtc internalizes from the cell surface in response to Hh (Denef et al. 2000; Zhu et al. 2003) and co-localizes with endosomes and multivesicular bodies (MVBs) (Capdevila et al. 1994b; Torroja et al. 2004) indicate that, similar to many other cell signaling systems (Polo and Di Fiore 2006), receptor endocytosis could also play a role in modulating the strength and duration of Hh signaling activity. In mammalian cells, removal of Ptch1 from the primary cilium in response to Shh binding is coupled to vSmo translocation into the cilium and downstream signaling activation (Rohatgi et al. 2007). Thus, Ptc subcellular localization and turnover need to be tightly controlled for proper Hh signal transduction. Here, we highlight recent studies that reveal the role of ubiquitination in regulating both $\mathrm{dPtc}$ and Ptch1 intracellular trafficking and turnover.

\section{The PPXY motif is essential for Ptc ubiquitination}

Multiple lines of evidence have suggested that the cytoplasmic C-tail of Ptc is important for its stability (Lu et al. 2006; Kawamura et al. 2008), which is mediated through interactions with the HECT domain E3 ligases (Lu et al. 2006; Huang et al. 2013; Chen et al. 2014; Yue et al. 2014). In Drosophila, yeast two-hybrid screens showed a PPXY motif within this 
region binds both Nedd4 and Smurf E3 ligases (Formstecher et al. 2005; Huang et al. 2013) and is required for Nedd4/Smurf interaction with dPtc (Lu et al. 2006; Huang et al. 2013). Mutation of Tyr in this consensus motif or truncation of the PPXY containing C-tail stabilizes dPtc protein (Lu et al. 2006). The PPXY motif has also been shown to regulate the stability of Ptch1 through interaction with several vertebrate Nedd4 family HECT domain E3 ligases including Nedd4, Smurf1, Smurf2, WWP2 and Itchy (Lu et al. 2006; Chen et al. 2014; Yue et al. 2014). In contrast to dPtc, Ptch1 possesses an additional PPXY motif in the third intracellular loop, and both PPXY motifs are important for the stability of Ptch1 protein (Yue et al. 2014).

Furthermore, Ptc protein lacking the PPXY motif(s) displays altered intracellular localization. In Drosophila, Hh induces the redistribution of dPtc from predominantly cell surface to predominantly intracellular (Denef et al. 2000; Zhu et al. 2003; Nakano et al. 2004). In contrast, dPtc lacking the portion of the C-tail that includes the PPXY motif remained at the plasma membrane in the presence of $\mathrm{Hh}$ (Lu et al. 2006). Interestingly, mutating the PPXY motif alone stabilized the dPtc protein, but did not block its internalization to the cytosol in response to $\mathrm{Hh}$ (Lu et al. 2006). Lu et al. speculate that this discrepancy may reflect a signaling role for PPXY in lysosomal targeting rather than for internalization, while other sequences in the $\mathrm{C}$-tail are additionally required for targeting $\mathrm{dPtc}$ from plasma membrane to endosomes. Whether this is indeed the case, and is specific to $\mathrm{dPtc}$, needs to be further investigated.

In vertebrates, it was also found that the PPXY motif containing C-tail regulates the localization of the Ptc protein. Wild-type Ptch1 protein showed increased co-localization with Caveolin-1-positive lipid rafts, Rab7-positive late endosomes and LAMP1 positive lysosomes in response to Shh treatment. In contrast, deletion of both PPXY motifs enhanced the co-localization of Ptch1 (Ptch1 $\Delta 2 \mathrm{PY}$ ) with Caveolin-1 in lipid rafts even in the absence of Shh. However, Ptch1 $\Delta 2 \mathrm{PY}$ failed to co-localize with Rab7 or LAMP1 positive vesicles when Shh was present (Yue et al. 2014). These findings suggest that the PPXY motifs mediate movement of Ptch1 from lipid rafts directly into late endosomes, which is consistent with observations that caveolin-associated cargos bypass early endosomes to enter late endosomes (Quirin et al. 2008; Hayer et al. 2010; Sandvig et al. 2011).

The PPXY motifs also seem to mediate ciliary trafficking of Ptch1. Shh signaling in vertebrate cells involves ciliary accumulation of vSmo with concurrent disappearance of Ptch1 from cilia (Rohatgi et al. 2007). While expression of wild-type Ptch1 in Ptchl ${ }^{-/-}$ mouse embryonic fibroblasts (MEFs) reconstituted this established ciliary trafficking pattern, Ptch1 $\triangle 2 \mathrm{PY}$ accumulated in the cilia in the presence or absence of Shh and appeared to partially reduce vSmo entry induced by Shh (Yue et al. 2014). Pharmacological inhibition of lysosomal turnover was also sufficient to block ciliary exit of wild type Ptch1 (Yue et al. 2014). Along with the finding that Ptch1 $\Delta 2 P Y$ accumulated in lipid rafts in the presence of Hh, the authors speculate that ciliary retention of the ubiquitination-deficient Ptch 1 that lacks both PPXY motifs in the presence of $\mathrm{Hh}$ is due to their inability to undergo endocytosis (Yue et al. 2014). 
In other organisms, it has been shown that ubiquitination of ciliary proteins may regulate their cellular localization. For example, in Chlamydomonas, free ubiquitin and ubiquitinconjugating enzyme have been detected in flagella, and the level of ubiquitinated proteins in flagella increases dramatically during flagellar resorption (Huang et al. 2009). In C. elegans, a protein kinase D2 (PKD2)-ubiquitin fusion is absent from cilia, whereas PKD2 normally remains in cilia at steady-state (Hu et al. 2007). Thus, it is conceivable to propose that $\mathrm{Ub}$ may be used as a tag for transport to the base of the cilium and also for further trafficking toward the degradative endocytic route (Nachury et al. 2010). Whether this mechanism is also involved in Hh-induced clearance of Ptch1 from the cilium needs to be further investigated.

\section{Smurfs dependent Ptc ubiquitination}

Two recent reports indicate that Smurf members of the HECT E3 ligase family negatively regulate Ptc by changing its subcellular localization and promoting its turnover (Huang et al. 2013; Yue et al. 2014). The first study by Huang et al. found that Smurf binds dPtc through the C-tail PPXY, and promotes Ub K48-linked and Ub K63-linked ubiquitination by targeting K1261 (Huang et al. 2013). Expression of dominant-negative (catalytically inactive) Smurf or RNAi against endogenous Smurf reduced ubiquitination of dPtc, which was dependent on the presence of the dPtc C-tail (Huang et al. 2013). Furthermore, Smurf overexpression decreased the steady state level of full-length dPtc protein but not that of the $\mathrm{C}$-tail truncated dPtc, indicating that Smurf ubiquitination of the C-tail promotes dPtc degradation (Huang et al. 2013).

Yue et al. examined the interaction of Smurfs and Ptch1 in the mammalian system and highlighted an important role of Ptch1 ubiquitination in its endocytic trafficking and degradation (Yue et al. 2014). Co-immunoprecipitation and FRET analysis indicated that Smurf1 or Smurf2 can bind Ptch1, and that this interaction is dependent on the presence of both PPXY motifs. Either deletion of the PPXY motifs or double knockout of both Smurf1 and Smurf2 stabilized Ptch1 protein both in the absence and presence of Shh, likely through abolishing Ptch1 ubiquitination. In agreement with the observed ubiquitination pattern in dPtc (Huang et al. 2013), re-introducing Smurf2 in the Smurf2 ${ }^{-/-}$MEFs enhanced K48 and K63-linked ubiquitination of Ptch1 (Yue et al. 2014). Together, these findings reveal essential functions for Smurf proteins in Ptch1 ubiquitination.

The mechanisms by which Smurfs mediate Ptc ubiquitination were examined both in Drosophila and in mammals. It is well established that activated Smo/Ci directly promotes the synthesis of Ptc through transcriptional induction (Goodrich et al. 1996). Recently, Huang et al. provided evidence to suggest that activated Hh signaling can also induce ubiquitination and degradation of the dPtc protein, likely through recruitment of Smurf to the plasma membrane by activated dSmo (Huang et al. 2013). By contrast, Yue et al. observed that Shh induced Ptch1 degradation in $\mathrm{Smo}^{-/-}$MEFs, indicating that Ptch1 turnover is mediated independently of vSmo (Yue et al. 2014). In agreement with these findings, dSmo but not vSmo was found to interact with Smurf(s) (Huang et al. 2013; Yue et al. 2014). The discrepancies observed in these studies suggest that although Smurf is 
important for Ptc turnover in both vertebrates and invertebrates, the mechanism through which this occurs is not fully conserved.

Consistent with a crucial role for Smurfs in targeting Ptc turnover, in vivo studies with multiple organisms suggest that the Smurf E3 ligases are positive modulators of the $\mathrm{Hh}$ signaling pathway. In Drosophila, knockdown of Smurf in wing discs decreased expression of Hh target genes, while ectopically expressed wild type Smurf but not catalytically inactive mutant Smurf increased Hh target gene expression (Huang et al. 2013). In zebrafish embryos, Smurf1 and Smurf2 knockdown by morpholinos disrupted proper somite development and reduced $\mathrm{Hh}$ target gene expression, which was rescued by knockdown of Ptch1 (Huang et al. 2013). In mice, knock-out or siRNA knockdown of Smurf1 and Smurf2 simultaneously inhibited Shh-dependent proliferation of granule cell precursors in the cerebellum (Yue et al. 2014). Collectively, these observations indicate that Smurf positively regulates Hh signaling by targeting Ptc for degradation.

\section{Itchy dependent Ptc ubiquitination}

Ptch1 has also been shown to function as a dependence receptor (Thibert et al. 2003). In the absence of Hh, Ptch1 promotes apoptosis by recruiting a dependosome type caspaseactivating complex through the binding of adaptors DRAL (downregulated in rhabdomyosarcoma LIM-domain protein) and TUCAN (family member 8 of the caspase recruitment domain containing proteins) to a pro-apoptotic domain located in the $\mathrm{C}$-tail of Ptch1 (Mille et al. 2009). Recent reports indicate that Nedd4 family of E3 ligases besides Smurfs have distinct functions in regulating this non-canonical function of Ptch1. Nedd4 was the first E3 ligase that was found to physically interact with Ptch1, but later reports show that Nedd4 does not downregulate Ptch1 and is involved instead in inducing Ptch1 triggered apoptosis (Fombonne et al. 2012; Yue et al. 2014). Specifically, Nedd4 was found to be a component of the dependosome complex, and was required for the ubiquitination and activation of caspase-9 (Fombonne et al. 2012). Nedd4 interaction with Ptch1 was unaffected by Shh, and was mediated by the proapoptotic domain of Ptch1 which does not contain the PPXY motifs (Fombonne et al. 2012). Another recent study revealed that ubiquitination of residue K1413 in the Ptch1 C-tail by a different Nedd4 family E3 ligase Itchy, which did bind through the PPXY motifs, is involved in regulating Ptch1 stability and localization in the absence of Hh signaling (Chen et al. 2014). Abolishing ubiquitination at this site through Lys to Arg mutation stabilized Ptch1, suppressed Itchy-induced degradation of Ptch1, and increased its plasma membrane localization (Chen et al. 2014). Notably, Itchy knockdown did not suppress Ptch1 degradation by Shh, while K1413R mutation reduced ubiquitination in both $\mathrm{Hh}$ treated and non-treated cells, indicating that Itchy regulates basal Ptch1 turnover in the absence of ligand (Chen et al. 2014). This function may be important in preventing Ptch1-induced apoptosis because K1413R mutation increased cell death and caspase-9 activity (Chen et al. 2014).

Together, these studies strongly suggest that the PPXY motifs share a conserved function from insects to vertebrates in recruiting the HECT E3 ligases to regulate Ptc intracellular localization and stability. In Drosophila, Nedd4, Smurf, and $\mathrm{Su}(\mathrm{dx})$ bound dPtc, but only Smurf has a positive role in regulating Hh signaling by targeting dPtc to ubiquitination ( $\mathrm{Lu}$ 
et al. 2006; Huang et al. 2013). Conversely, knockdown of Nedd4 had no effect on Hh signaling activity while $\mathrm{Su}(\mathrm{dx})$ was shown to negatively regulate $\mathrm{Hh}$ signaling pathway (Huang et al. 2013). Su(dx) is the Drosophila homolog of Itchy, which was found to negatively regulate $\mathrm{Hh}$ signaling activity in mammals by targeting Gli1 (Di Marcotullio et al. 2006) (see the "Degradation of Gli1" section). Thus, it is possible that $\mathrm{Su}(\mathrm{dx})$ may analogously suppress the Drosophila Hh signaling pathway by targeting Ci. Similarly, in mammalian cells, multiple Nedd4 family HECT E3 ligases were found to interact with Ptch1, but not all of them promote Ptch1 turnover. Only Smurf1/Smurf2 or Itchy coexpression promoted Ptch1 ubiquitination and degradation, while Nedd4 is involved in the apoptotic activity of Ptch1 (see above). In summary, these studies strongly suggest that HECT E3 ligases have distinct, possibly non-overlapping functions in regulating Ptc expression and activity. Additional studies are needed to clarify the functions of the individual Ptc-interacting HECT E3 ligases in both Drosophila and vertebrates, as well as the mechanisms by which they regulate Ptc.

\section{Regulation of Smo through ubiquitination}

The physiological mechanisms that influence Smo activity in Hh-responsive cells remain a key question in the study of Hh signal transduction. Activated Smo accumulates at the plasma membrane in Drosophila cells (Denef et al. 2000; Zhu et al. 2003) or in the primary cilium in vertebrates (Corbit et al. 2005; Rohatgi et al. 2009). Hh-induced phosphorylation of dSmo through protein kinase A (PKA) and casein kinase 1 (CK1) was reported to promote its cell surface localization (Jia et al. 2004; Zhang et al. 2004; Apionishev et al. 2005; Chen et al. 2011a), whereas GRK2 and CK1a-dependent phosphorylation of vSmo was found to be crucial for its ciliary accumulation (Chen et al. 2011a). While phosphorylation has been fairly well established as an important positive regulatory mechanism that promotes the subcellular trafficking and activation of Smo, a growing body of evidence indicates that ubiquitination is involved in negative regulation of Smo through the endocytic pathway.

Two recent studies provided both genetic and biochemical evidence to suggest a role for ubiquitination in regulating dSmo subcellular localization and activity (Li et al. 2012; Xia et al. 2012). One study by Li et al. showed that Drosophila wing disc cells lacking the only E1 ubiquitin-activating enzyme Uba1 accumulated higher levels of endogenous dSmo on the cell surface, and RNAi or pharmacological (PYR-41) inhibition of Uba1 in S2 cells increased the cell surface localization of dSmo (Li et al. 2012). In the other study by Xia et al., an extra structure between Vein 2 and Vein 3, an indicator of ectopic Hh signaling activity, was observed in fly lines expressing wild type dSmo, but not dSmo fused to a single Ub molecule (Xia et al. 2012). The E3 ligase(s) that catalyze(s) dSmo ubiquitination has remained elusive but UBPY/USP8 was identified as the specific deubiquitinase (DUB) required for Hh-induced deubiquitination and cell surface accumulation of dSmo ( $\mathrm{Li}$ et al. 2012; Xia et al. 2012). Together, these data show that ubiquitination negatively regulates the cell surface accumulation and activity of dSmo.

dSmo can be both multi-mono- and polyubiquitinated, leading to its endocytosis and degradation by both lysosome- and proteasome-dependent mechanisms (Li et al. 2012; Xia

Front Biol (Beijing). Author manuscript; available in PMC 2015 September 09. 
et al. 2012). The mediators linking ubiquitination of dSmo and the endocytic pathway have begun to be characterized. The endosomal sorting complex required for transport (ESCRT) machinery facilitates the trafficking of ubiquitinated proteins from endosomes to lysosomes via MVBs (Williams and Urbe 2007). Homologs of several ESCRT components were found to play important roles in endosomal sorting of ubiquitinated dSmo. Both Hh pathway activation and dSmo accumulation have been observed in wing imaginal disc cells that had mutated hrs (HGF-regulated tyrosine kinase substrate), a component of the ESCRT-0 complex (Jekely and Rorth 2003; Li et al. 2012; Fan et al. 2013), tsg101 (Tumor susceptibility gene 101) of the ESCRT-I complex (Li et al. 2012) or vps36 (Vacuolar protein sorting 36) of the ESCRT-II complex (Yang et al. 2013). Specifically, mutating the ESCRT-0 component $h r s$ and the ESCRT-I component $t s g 101$ resulted in dSmo accumulation in Rab7 and Lamp1 positive late endosomes (Fan et al. 2013), while perturbation of ESCRT-II component vps36 caused dSmo accumulation at plasma membrane and endosomes (Yang et al. 2013). Taken together, different ESCRT complexes mediate Hh signaling activity via downregulating ubiquitinated dSmo proteins at different levels of the endocytic pathway.

In the absence of Hh, dSmo is ubiquitinated at multiple Lys residues in its cytoplasmic part, including the internal loops and the C-tail (Li et al. 2012; Xia et al. 2012; Fan et al. 2013; Yang et al. 2013). Remarkably, Hh-induced dSmo phosphorylation through PKA/CK1 also occurs within the dSmo C-tail (Jia et al. 2004; Zhang et al. 2004; Apionishev et al. 2005), at an autoinhibitory domain (SAID) that prevents dSmo cell surface accumulation in its unphosphorylated state (Zhao et al. 2007). The SAID domain is both necessary and sufficient to promote ubiquitination and internalization of dSmo ( $\mathrm{Li}$ et al. 2012). Moreover, Hh stimulation fails to inhibit dSmo ubiquitination in the presence of a PKA inhibitor H-89, and overexpression of a constitutively active PKA blocks dSmo ubiquitination in the absence of $\mathrm{Hh}$ ( $\mathrm{Li}$ et al. 2012). Together, these data indicate that Hh inhibits dSmo ubiquitination and internalization through PKA/CK1-mediated phosphorylation of the SAID domain in the $\mathrm{dSmo} \mathrm{C-tail.} \mathrm{Conversely,} \mathrm{dSmo} \mathrm{ubiquitination} \mathrm{was} \mathrm{also} \mathrm{found} \mathrm{to} \mathrm{negatively}$ regulate its phosphorylation. For instance, the ESCRT-0 component Hrs was found to block dSmo phosphorylation by interacting with the SAID domain (Fan et al. 2013).

The mechanism by which Hh inhibits dSmo ubiquitination via phosphorylation is not well understood. Xia et al. reported that phosphorylation of dSmo promoted the formation of a dSmo-UBPY/USP8 complex, while Li et al. found that the association between dSmo and UBPY/USP8 was not significantly affected either by Hh stimulation or dSmo phosphorylation ( $\mathrm{Li}$ et al. 2012; Xia et al. 2012). Alternatively, the mechanism underlying the regulation of dSmo ubiquitination might involve interaction of dSmo with an E3 ligase rather than DUBs. Thus, identifying the E3 ligase(s) involved in dSmo ubiquitination may shed important insights on the mechanism by which $\mathrm{Hh} /$ phosphorylation-mediated dSmo ubiquitination occurs.

In mammals, ubiquitination of vSmo was also found to be reduced in the presence of $\mathrm{Hh}$ ligands, indicating that ubiquitination is a conserved mechanism for Smo regulation (Xia et al. 2012). Hh-dependent activation of both dSmo and vSmo involves phosphorylation, which was found to counteract ubiquitination of dSmo (Chen et al. 2011a; Li et al. 2012); 
thus the possible interplay between vSmo phosphorylation and ubiquitination should also be investigated. Furthermore, activation of both $\mathrm{dSmo}$ and vSmo requires their accumulation at the plasma membrane or primary cilium, respectively. Since ubiquitination inhibits the plasma membrane localization of dSmo, one might speculate that ubiquitination plays an analogous role in vSmo trafficking into the primary cilium. For example, $\beta$-arrestins in association with integrin-linked kinase (Izzi et al.) play an important role in Shh-induced vSmo ciliary translocation by mediating interaction with the intraflagellar transport (IFT) protein Kif3a (Kovacs et al. 2008; Barakat et al. 2013). Could ubiquitination play a role in counteracting the ciliary transport of vSmo by abrogating its interaction with one or more of these components in the absence of Shh?

\section{Regulation of Sufu through ubiquitination}

Sufu is a conserved inhibitory component of the Hh signaling pathway that regulates the localization, activity, and stability of Ci/Gli transcription factors. In both Drosophila and mammals, Sufu directly binds to the $\mathrm{Ci} / \mathrm{Gli}$ proteins to prevent their nuclear translocation (Ding et al. 1999; Kogerman et al. 1999; Methot and Basler 2000; Wang et al. 2000b; Humke et al. 2010). In addition, mammalian Sufu functions in the nucleus to repress Glidependent transcription by interacting with the SAP18-mSin3 HDAC (histone deacetylase) complex (Cheng and Bishop 2002; Paces-Fessy et al. 2004). Sufu appears to have dual roles in stabilization of $\mathrm{Ci} / \mathrm{Gli}$. Interaction with Sufu was found to protect the full-length $\mathrm{Ci} / \mathrm{Gli} 2 / 3$ proteins from degradation by the Cul3-HIB (Hh-induced MATH and BTB domain containing protein)/SPOP (speckle-type POZ protein) E3 ligase complex (Zhang et al. 2006a; Chen et al. 2009; Humke et al. 2010; Wang et al. 2010), and to promote GSK3 $\beta$ dependent processing of Gli3 to the repressor form by Cul1-Slimb/ßTrCP (Kise et al. 2009). Recent investigations indicate that the localization and stability of Sufu itself are also tightly controlled. Here, we review the role of ubiquitin-proteasome system in Sufu regulation.

It was found that mammalian Sufu protein was ubiquitinated and degraded in response to Shh signaling (Yue et al. 2009). In the NCI-H322M cells, a human lung cancer cell line with high level of Sufu turnover, Sufu protein levels were stabilized when upstream Shh signaling was inhibited by the Smo antagonist cyclopamine (Yue et al. 2009). By contrast, decreased Sufu protein levels were observed in embryonic tissue from $\mathrm{Ptch}^{-/-}$mutant mice with increased Hh signaling activity and in wild-type MEFs treated with Shh ligand or Smo agonist (Yue et al. 2009). Similar to the observation in the NCI-H322M cells, cyclopamine also inhibited Shh-induced Sufu degradation in MEFs (Yue et al. 2009). The authors also found that ubiquitination of endogenous Sufu protein increased in the presence of Shh. Thus the Hh signaling-induced Sufu turnover may be related to ubiquitin-proteasome-mediated degradation of Sufu (Yue et al. 2009). Both mono and poly-ubiquitinated Sufu proteins were detected when co-expressed with HA-tagged ubiquitin in HEK293 cells. Mass spectrometry identified Lys residue K257 as the site of Sufu mono-ubiquitination (Yue et al. 2009). When compared to the wild type Sufu, the K257R mutant more efficiently repressed both the proliferation of NCI-H322M cells and the Gli-mediated transcription in Sufu-deficient MEFs (Yue et al. 2009). However, K257 is unlikely to be the only site where Sufu is ubiquitinated because K257R mutation stabilized, but did not completely inhibit Sufu turnover in the NCI-H322M cells (Yue et al. 2009). Although these findings suggest Sufu 
ubiquitination and turnover comprise a novel layer of regulation in Hh signal transduction, the E3 ligase and additional ubiquitin attachment sites responsible for Shh-induced Sufu turnover await to be identified. Another study from the same group recently showed that PKA and GSK3 $\beta$ dependent phosphorylation can counteract Shh induced degradation of Sufu (Chen et al. 2011b). However, whether phosphorylation can affect Sufu ubiquitination needs to be further investigated.

Hh signaling induced downregulation of Sufu was also observed in flies and requires HIB, the substrate recognition and binding component of Cul3-HIB E3 ligase complex (Liu et al. 2014a). Either activating Hh signaling or overexpressing HIB in the wing imaginal disc promoted degradation of Sufu (Zhang et al. 2006a; Liu et al. 2014a). HIB itself is upregulated by the Hh signal (Zhang et al. 2006a), and mutant clones that lack HIB had elevated Sufu protein levels, while re-expression of HIB along with Hh restored Sufu downregulation (Liu et al. 2014a). These findings could be recapitulated when HIB was replaced by its mammalian homolog SPOP, indicating that HIB regulation of Sufu protein levels through $\mathrm{Hh}$ signaling may be conserved from flies to mammals (Liu et al. 2014a). Disrupting the Cul3-HIB complex, Cul3 E3 ligase activity, proteosomal activity, or polyubiquitination stabilized Sufu protein. However, in contrast to the direct ubiquitination of Sufu observed in mammalian cells (Yue et al. 2009), HIB did not target Sufu itself for degradation in Drosophila, nor did it affect nuclear export or levels of Sufu mRNA when overexpressed (Liu et al. 2014a).

Considering that the HIB E3 ligase activity is necessary for Sufu downregulation, the authors predicted HIB may inhibit Sufu through turnover of an intermediate factor (Liu et al. 2014a). An RNAi based screen that targeted putative HIB-interacting proteins revealed that the spliceosome factor Crn (Crooked neck) is involved in downregulating Sufu (Liu et al. 2014a). Accordingly, genetic and biochemical experiments showed that Crn knockdown attenuated Hh or HIB induced Sufu downregulation (Liu et al. 2014a). Although Crn was identified as a putative HIB interacting protein based on a yeast two hybrid assay, binding of HIB and Crn was not observed in co-immunoprecipitation experiments (Liu et al. 2014a). Interestingly, HIB promoted Crn accumulation in the nucleus, an effect that was blocked by a proteasome inhibitor and which correlated with a small but noticeable reduction of Sufu levels in wing disc cells (Liu et al. 2014a). Based on these findings, the authors suggest that Cul3-HIB degrades an unknown factor required for nuclear export of $\mathrm{Crn}$, and the resulting nuclear accumulation of Crn downregulates Sufu expression by inhibiting formation of functional Sufu mRNA (Liu et al. 2014a). However, the identity of the unknown HIB substrate and the exact mechanism by which Crn regulates Sufu expression await future investigation.

\section{Regulation of Ci/Gli transcription factors by ubiquitination}

Ubiquitin modification of the $\mathrm{Ci} / \mathrm{Gli}$ transcription factors serves as an important mechanism to suppress Hh pathway activity. Members of both the RING and HECT families of E3 ligases function as part of multi-protein complexes to target $\mathrm{Ci} / \mathrm{Gli}$ for ubiquitination and proteolysis. In the absence of $\mathrm{Hh}$, partial degradation of both $\mathrm{Ci}$ and $\mathrm{Gli} 2 / 3$ convert them into truncated forms that function as transcriptional repressors of the Hh pathway, whereas 
the full-length forms are rendered inactive (Hui and Angers 2011). In the presence of Hh, formation of the $\mathrm{Ci} / \mathrm{Gli} 2 / 3$ truncated repressors is blocked and the full-length forms become activated (Hui and Angers 2011). Hh also stimulates complete degradation of full-length $\mathrm{Ci} /$ Gli2/3, which serves as a feedback control to limit their activity after pathway activation (Hui and Angers 2011). In contrast to $\mathrm{Ci} / \mathrm{Gli} 2 / 3$, Gli1 does not generate repressor forms and instead functions exclusively as an activator. By focusing on Gli1, additional molecular mechanisms that govern Gli protein ubiquitination and degradation have been uncovered (see below). Here, we will briefly summarize the different E3 ligase complexes and the mechanisms involved in proteolytic processing and degradation of the $\mathrm{Ci} / \mathrm{Gli}$ transcription factors. We will also turn our attention to recent studies that reveal novel ubiquitindependent mechanisms that control Gli protein function independently of Gli degradation. Due to space limitations and the extensive body of literature on regulation of $\mathrm{Ci} / \mathrm{Gli}$ by ubiquitination, we would like to refer readers to the more detailed reviews that are cited here (Jiang 2006; Di Marcotullio et al. 2007; Hui and Angers 2011; Gulino et al. 2012).

\section{Processing and degradation of $\mathrm{Ci}$ and Gli2/3}

The RING finger-based Skip1-Cul1-F-box (SCF) E3 ligase complex targets Ci and Gli2/3 for partial proteolytic degradation to generate the carboxy-terminally truncated repressor forms. In the absence of $\mathrm{Hh}, \mathrm{Ci}$ ubiquitination by SCF is promoted by PKA, GSK3 and CK1-dependent phosphorylation at multiple sites in the C-terminus of $\mathrm{Ci}$ (Jia et al. 2002; Price and Kalderon 2002; Jia et al. 2005; Smelkinson and Kalderon 2006; Tempe et al. 2006; Wang and Li 2006). The kinesin-like scaffolding protein Cos2 is required for $\mathrm{Ci}$ phosphorylation and may function to recruit these kinases for Ci processing (Zhang et al. 2005). The presence of Hh inhibits Cos2-kinase complex formation, as well as the phosphorylation and processing of $\mathrm{Ci}$ (Chen et al. 1999; Wang et al. 1999; Wang and Holmgren 1999; Zhang et al. 2005). In-vitro binding analysis showed that phosphorylation of $\mathrm{Ci}$ by all three kinases conferred binding to the F-box protein Slimb, which functions as the substrate recognition component of the SCF E3 ligase complex (hereafter referred to as Cul1-Slimb in Drosophila) (Jia et al. 2005; Smelkinson and Kalderon 2006). In vertebrates, a similar phosphorylation-dependent mechanism involving PKA, GSK3 $\beta$, and CK1 targets Gli3 and, to a lesser extent, Gli2, for ubiquitination and processing to the repressor form by promoting their binding to $\beta \mathrm{TrCP}$, the vertebrate homolog of Slimb (hereafter referred to as Cul1- $\beta$ TrCP to denote the vertebrate SCF E3 ligase complex) (Bhatia et al. 2006; Wang and Li 2006; Pan et al. 2009). Detailed genetic and biochemical analyses indicate that ciliary localization of Gli2 and Gli3 is required for formation of the activator and repressor forms (Haycraft et al. 2005; Huangfu and Anderson 2005; Liu et al. 2005; May et al. 2005; Santos and Reiter 2014). However, it is unclear how ciliary trafficking of Gli proteins is linked to their ubiquitination and degradation by Cul1- $\beta \operatorname{TrCP}$, especially in light of the finding that PKA activation inhibits Gli3 accumulation in primary cilia (Wen et al. 2010; Zeng et al. 2010).

In contrast to Cul1-based E3 ligases, Cul3-based E3 ligases target $\mathrm{Ci}$ and Gli2/3 proteins for complete degradation in the presence of Hh (Kent et al. 2006; Zhang et al. 2006a). In vertebrates, only the full-length activator forms of Gli2 and Gli3 are targeted for ubiquitination and complete proteolysis by Cul3 E3 ligase, which is promoted through the 
substrate-binding adaptor SPOP (Wang et al. 2010), and inhibited by Sufu which in turn appears to antagonize the activity of SPOP (Chen et al. 2009). Unlike $\beta$ TrCP-based processing of Gli, SPOP-based degradation of Gli2 and Gli3 may occur independently of primary cilium because Gli2/3 and SPOP colocalization was observed in $\mathrm{Kif}_{3} \mathrm{a}^{-/-}$MEFs which lack cilia (Chen et al. 2009). The Drosophila homolog of SPOP, HIB, promotes Cul3based ubiquitination and degradation of $\mathrm{Ci}$ in the presence of $\mathrm{Hh}$ (Kent et al. 2006; Zhang et al. 2006a). HIB-mediated degradation of $\mathrm{Ci}$ is also inhibited by Sufu, indicating that the mechanism by which HIB/SPOP regulates $\mathrm{Ci} / \mathrm{Gli}$ is evolutionarily conserved between flies and mammals (Zhang et al. 2006a).

Recently, insights into the mechanisms that underlie the differential outcomes of Cul1-based versus Cul3-based ubiquitination on $\mathrm{Ci} / \mathrm{Gli}$ proteolysis have begun to emerge. Cul1-based E3 ligase was found to add both K11-linked and K48-linked ubiquitin chains to Ci, while Cul3-based E3 ligase added mainly K48-linked chains (Zhang et al. 2013). The Cul1mediated partial degradation of $\mathrm{Ci} / \mathrm{Gli3}$ required Ter94/p97 ATPase which selectively bound K11-linked ubiquitin chains on $\mathrm{Ci}$ as well as components of the Cul1-Slimb complex (Zhang et al. 2013). These observations indicate that differences in the pattern of $\mathrm{Ci} / \mathrm{Gli} 3$ ubiquitination through Cul1- or Cul3-based E3 ligases determine the mode of proteolytic processing, and that Ter94 mediates recruitment of Cul1-ubiquitinated $\mathrm{Ci} / \mathrm{Gli} 3$ for partial degradation. However, Gli1/2 are targeted by Cul1- $\beta \operatorname{TrCP}$ for ubiquitination and complete degradation, suggesting that differences in the amino acid sequence of Gli1/2 versus Ci/Gli3 may determine the predominant outcome of ubiquitin-mediated proteolysis by the same Cul1-3TrCP E3 ligase (Bhatia et al. 2006; Huntzicker et al. 2006; Pan et al. 2009). Furthermore, Gli2 stability was found to be modulated by multiple protein kinases such as MEK, which antagonizes GSK3 $\beta$-mediated phosphorylation and subsequent ubiquitination of Gli2 (Varjosalo et al. 2008; Liu et al. 2014b). Thus, multiple protein kinases, possibly through synergism with other signaling pathways, regulate Gli2/3 stability by promoting or inhibiting Cul1- $\beta \operatorname{TrCP}$ mediated ubiquitination.

\section{Degradation of Gli1}

A substantial body of evidence reveals that the constitutive transcriptional activator Gli1 is targeted by multiple E3 ligases, including members of the RING and HECT E3 families. Huntzicker et al. found that $\beta \operatorname{TrCP}$ associates with Gli1 through a carboxy-terminal degron DSGXXS motif (Dc) that is conserved among the vertebrate Gli homologs (Huntzicker et al. 2006). It should be noted that although $\mathrm{Ci}$, Gli1, and Gli3 are all targeted by $\beta \operatorname{TrCP}$ for proteolysis, only Gli1 is completely degraded. Deletion of the Dc or abrogating PKA phosphorylation of Gli1 inhibited the interaction with $\beta \operatorname{TrCP}$ and thus stabilized the Gli1 protein (Huntzicker et al. 2006). A second highly conserved degron motif found at the Nterminus $\left(\mathrm{D}_{\mathrm{N}}\right)$ also mediates Gli1 stability, but functions independently of the $\beta \operatorname{TrCP}$ and Sufu through a currently unidentified mechanism (Huntzicker et al. 2006). Di Marcotullio et al. found that the adaptor protein Numb targets Gli1 for ubiquitination and proteolytic degradation mediated by the HECT E3 ligase Itchy, which is dependent on Itchy binding to two PPXY and a pSP motif in the Gli1 C-terminus (Di Marcotullio et al. 2006; Di

Marcotullio et al. 2011). Numb activates Itchy by disrupting its autoinhibitory conformation, resulting in Itchy association with and ubiquitination of Gli1 (Di Marcotullio et al. 2011). 
Increased Gli1 protein stability and transcriptional activity were observed when the authors mutated the Itchy binding sites or the Dc motif that is recognized by $\beta$ - TrCP (Huntzicker et al. 2006; Di Marcotullio et al. 2011). This observation indicates that the activity of multiple E3 ligases act to suppress Gli1 transcriptional output by promoting its degradation.

Recently, other types of E3 ligases were found to be involved in regulating Gli1 activity as part of the DNA-damage response in which genotoxic stress attenuates Gli1 mitogenic and pro-survival properties. Mazza et al. identified PCAF (p53-mediated elevation of the acetyltransferase p300/CBP-associated factor) as a novel E3 ligase for Gli1 that functions to link the p53-mediated DNA damage response and suppression of $\mathrm{Hh} / \mathrm{Gli}$ signaling in medulloblastoma cells (Mazza et al. 2013). Inducing genotoxic stress by drug treatment increased p53-dependent upregulation of PCAF, which was required to inhibit Gli1mediated growth and survival by promoting its ubiquitination and degradation. Furthermore, drug-induced growth arrest and apoptosis were dependent on PCAF and its ability to induce Gli1 degradation (Mazza et al. 2013). Gilder et al. showed that Gli1 ubiquitination and suppression of Gli1-dependent transcriptional activity were promoted by Fem1b, a conserved adaptor protein that mediates interaction with E3 ligase complexes that contain Cul2/Elongin-BC subunits (Gilder et al. 2013). Exogenous Fem1b decreased expression of Gli1 mRNA in a colon cancer cell line for which Gli1 had previously been shown to promote cell survival and the DNA damage response (Mazumdar et al. 2011; Agyeman et al. 2012; Gilder et al. 2013). However, it is unclear whether Fem1b is required for Gli1 inhibition during the DNA damage response, and the mechanism by which this may occur has not been fully explored. In summary, these findings indicate that the action of multiple E3 ligases impinge on Gli to regulate Hh signaling output in different cellular contexts, and may thus influence the tumorigenesis, growth, or drug response of Hh-dependent malignancies.

\section{Indirect regulation of Gli1/2 by ubiquitination-dependent mechanisms}

Degradation is not the only mechanism through which ubiquitination can regulate $\mathrm{Ci} / \mathrm{Gli}$. A recent study in Drosophila found that Hyd (hyperplastic discs), a HECT E3 ligase that had previously been shown to negatively regulate Hh signaling (Lee et al. 2002), interacted with but did not target $\mathrm{Ci}$ for degradation (Wang et al. 2014). Instead, Hyd selectively restrains the transcriptional activity of $\mathrm{Ci}$ at specific $\mathrm{Hh}$ target gene promoters through an undefined mechanism that requires its E3 ligase activity (Wang et al. 2014). Another recent study revealed an indirect ubiquitination-dependent mechanism regulates Gli1 and Gli2 activity through suppressing HDAC. Gli1 and Gli2 can be acetylated, and their HDAC-mediated deacetylation represents a transcriptional switch in which deacetylation promotes transcriptional activation and sustains a positive autoregulatory loop through Hh-induced upregulation of HDAC1 (Canettieri et al. 2010). This mechanism is turned off by HDAC1 degradation through a Cul3-KCASH (KCTD containing, Cullin3 adaptor, suppressor of Hedgehog) E3 ligase complex (Canettieri et al. 2010; De Smaele et al. 2011). Remarkably, the KCASH1 gene is frequently deleted in human medulloblastoma, and KCASH2/3 overexpression reduces the Hh-dependent growth of medulloblastoma cell lines (Canettieri et al. 2010; De Smaele et al. 2011). These findings highlight the relevance of the interplay 
between ubiquitination and acetylation events and provide new targets for Hh signalingdependent cancer therapy.

\section{Concluding Remarks}

Growing evidence suggests that ubiquitination plays important roles in regulating $\mathrm{Hh}$ signaling activity by targeting several key pathway components, including Ptc, Smo, Sufu and $\mathrm{Ci} / \mathrm{Gli}$ proteins (Figure 1). Ubiquitination has the net effect of counteracting the function of each of these key components by decreasing their protein levels through degradation, and, in the cases of Ptc and Smo, by changing their subcellular localization. Conserved HECT and RING family E3 ligases that target Ptc and Ci/Gli have been identified (Table 1). Ubiquitination of Ptc by Smurf E3 ligases is required during endocytosis and for subsequent Ptc protein turnover in response to active Hh signaling. Two Cullin-based E3 ligases mediate $\mathrm{Ci} / \mathrm{Gli}$ function and stability: Cul1-Slimb/ $\mathrm{TTrCP}$ processes $\mathrm{Ci} / \mathrm{Gli}$ into repressor forms in the absence of Hh signaling, and Cul3-HIB/SPOP degrades $\mathrm{Ci} / \mathrm{Gli}$ in the presence of Hh signaling. The dual roles of $\mathrm{Ci} / \mathrm{Gli}$ ubiquitination support the notion that fine tuning of Hh signaling output occurs through downregulation of Cul1-based repressor formation and upregulation of Cul3-based Ci/Gli degradation (Di Marcotullio 2007). Smo ubiquitination prevents its plasma membrane localization in the absence of $\mathrm{Hh}$, while Sufu ubiquitination promotes its degradation in the presence of Hh. The specific E3 ligases that target Smo and Sufu have not yet been identified, although HIB/SPOP was found to reduce Sufu protein synthesis indirectly. Collectively, these findings indicate that multiple concerted ubiquitination events impinge on Ptc, Smo, Sufu, and Ci/Gli to influence Hh signaling output.

Several areas regarding the roles and mechanisms of ubiquitination in Hh signaling clearly deserve further investigation. Reversible ubiquitination of the key signaling components likely confers versatility in influencing the outcome of the Hh pathway. Aside from specific targeting of Smo by the UBPY/USP8 (Li et al. 2012; Xia et al. 2012), very little is known about whether DUBs are involved in reversing the ubiquitination of Ptc, Sufu, and Ci/Gli, or how such DUBs may be regulated in the context of Hh signaling. While formation of K48linked polyubiquitin chains on Smo, Sufu, and Ci/Gli correlates with their protein degradation, the precise nature of the ubiquitin chains and their critical target Lys residues have not been fully unraveled (Table 1). The interplay of ubiquitination with other posttranslational modifications - such as phosphorylation - should also be further explored in regards to how integration of multiple post-translational modifications by the Hh pathway components can determine the extent and duration of Hh signaling.

The observation that Itchy can target both Ptc and Gli raises the possibility that other E3 ligases may have multiple targets in the Hh signaling pathway (Di Marcotullio et al. 2006; Chen et al. 2014). The significance of having different Hh pathway components targeted by the same E3 ligase should also be explored. For example, Itchy-mediated degradation of Ptch1 in the absence of Hh prevents apoptosis, while Itchy targeting of Gli1 is promoted by the Numb adaptor in differentiating cells. It is unclear if the outcomes of these two events are mutually exclusive, or if distinct molecular mechanisms determine whether Itchy targets Ptch1 or Gli1 for ubiquitination. Might the presence of Numb divert the binding of Itchy 
from Ptch1 to Gli1? Multiple E3 ligases can also target the same Hh pathway component, which may play distinct roles depending on cellular context. This notion is supported by findings that both Smurf and Itchy ubiquitinate Ptch1, with Smurf acting as a positive modulator of Hh signaling activity and Itchy acting as a negative modulator of Ptch1dependent apoptosis (Huang et al. 2013; Chen et al. 2014; Yue et al. 2014). The mechanism(s) that determine which of these HECT E3 ligases interact with Ptch1 need to be investigated. It may involve, for example, tissue-specific expression level of the HECT E3 ligases, or a change in the conformation or post-translational modification of the Ptch1 Ctail. In summary, these findings underscore the need for further studies to understand the molecular mechanisms by which E3 ligases are activated and recognize Hh pathway components.

Ubiquitination of Hh pathway components may have physiological roles in Hh signalingrelated developmental processes and cancer formation. This notion is supported by evidence linking the control of Gli protein degradation with tumorigenesis. Expression of mutant Gli1 lacking the two degron motifs in the epidermis accelerated formation of tumors in mice that clinically resemble basal cell carcinoma (Huntzicker et al. 2006). Mutation of Itchy E3 ligase binding sites in Gli1 enhanced the proliferation, anchorage-independent growth, and migration of medulloblastoma cell lines (Di Marcotullio et al. 2011). The Gli1 mutant also conferred resistance to the inhibitory effect of Numb, which was found to suppress progenitor-cell maintenance and growth by antagonizing Hh signaling through its cooperation with Itchy (Di Marcotullio et al. 2006; Di Marcotullio et al. 2011). Thus, the regulation of Gli1 stability and function by multiple E3 ligases may influence Gli1 oncogenic potential in vivo. It is not yet clear whether the ubiquitination of other $\mathrm{Hh}$ pathway components is also involved in Hh signaling-related tumorigenesis. If it was found to be the case, E3 ligases that specifically downregulate negative players of Hh pathway, such as Smurfs, could serve as attractive candidates for biological or chemical inhibitors, thus opening a new route for treatment of Hh signaling related cancers.

\section{Acknowledgements}

We apologize to colleagues whose works were not cited owing to space limitations. We also thank Masaki Kato, Adrian Creanga, and Navdar Sever for their critical reading of the manuscript and commentary. Our work is supported by funding from the National Institutes of Health.

\section{References}

Agyeman A, Mazumdar T, Houghton JA. Regulation of DNA damage following termination of Hedgehog $(\mathrm{HH})$ survival signaling at the level of the GLI genes in human colon cancer. Oncotarget. 2012; 3:854-868. [PubMed: 23097684]

Allen BL, Song JY, Izzi L, Althaus IW, Kang JS, Charron F, Krauss RS, McMahon AP. Overlapping roles and collective requirement for the coreceptors GAS1, CDO, and BOC in SHH pathway function. Developmental cell. 2011; 20:775-787. [PubMed: 21664576]

Apionishev S, Katanayeva NM, Marks SA, Kalderon D, Tomlinson A. Drosophila Smoothened phosphorylation sites essential for Hedgehog signal transduction. Nature cell biology. 2005; 7:8692. [PubMed: 15592457]

Aza-Blanc P, Lin HY, Ruiz i Altaba A, Kornberg TB. Expression of the vertebrate Gli proteins in Drosophila reveals a distribution of activator and repressor activities. Development. 2000; 127:4293-4301. [PubMed: 10976059] 
Aza-Blanc P, Ramirez-Weber FA, Laget M-P, Schwartz C, Kornberg TB. Proteolysis that is inhibited by hedgehog targets Cubitus interruptus protein to the nucleus and converts it to a repressor. Cell. 1997; 89:1043-1053. [PubMed: 9215627]

Bai CB, Auerbach W, Lee JS, Stephen D, Joyner AL. Gli2, but not Gli1, is required for initial Shh signaling and ectopic activation of the Shh pathway. Development. 2002; 129:4753-4761. [PubMed: 12361967]

Bai CB, Stephen D, Joyner AL. All mouse ventral spinal cord patterning by hedgehog is Gli dependent and involves an activator function of Gli3. Developmental cell. 2004; 6:103-115. [PubMed: 14723851]

Barakat B, Yu L, Lo C, Vu D, De Luca E, Cain JE, Martelotto LG, Dedhar S, Sadler AJ, Wang D, et al. Interaction of smoothened with integrin-linked kinase in primary cilia mediates Hedgehog signalling. EMBO reports. 2013; 14:837-844. [PubMed: 23877428]

Baumeister W, Walz J, Zuhl F, Seemuller E. The proteasome: paradigm of a self-compartmentalizing protease. Cell. 1998; 92:367-380. [PubMed: 9476896]

Beachy PA, Hymowitz SG, Lazarus RA, Leahy DJ, Siebold C. Interactions between Hedgehog proteins and their binding partners come into view. Genes \& development. 2010; 24:2001-2012. [PubMed: 20844013]

Beachy PA, Karhadkar SS, Berman DM. Tissue repair and stem cell renewal in carcinogenesis. Nature. 2004; 432:324-331. [PubMed: 15549094]

Bhatia N, Thiyagarajan S, Elcheva I, Saleem M, Dlugosz A, Mukhtar H, Spiegelman VS. Gli2 is targeted for ubiquitination and degradation by beta-TrCP ubiquitin ligase. The Journal of biological chemistry. 2006; 281:19320-19326. [PubMed: 16651270]

Bitgood MJ, Shen L, McMahon AP. Sertoli cell signaling by Desert hedgehog regulates the male germline. Current Biology: CB. 1996:298-304. [PubMed: 8805249]

Briscoe J, Chen Y, Jessell TM, Struhl G. A hedgehog-insensitive form of patched provides evidence for direct long-range morphogen activity of sonic hedgehog in the neural tube. Mol Cell. 2001; 7:1279-1291. [PubMed: 11430830]

Briscoe J, Therond PP. The mechanisms of Hedgehog signalling and its roles in development and disease. Nature reviews Molecular cell biology. 2013; 14:416-429. [PubMed: 23719536]

Buttitta L, Mo R, Hui CC, Fan CM. Interplays of Gli2 and Gli3 and their requirement in mediating Shh-dependent sclerotome induction. Development. 2003; 130:6233-6243. [PubMed: 14602680]

Canettieri G, Di Marcotullio L, Greco A, Coni S, Antonucci L, Infante P, Pietrosanti L, De Smaele E, Ferretti E, Miele E, et al. Histone deacetylase and Cullin3-REN(KCTD11) ubiquitin ligase interplay regulates Hedgehog signalling through Gli acetylation. Nature cell biology. 2010; 12:132-142. [PubMed: 20081843]

Capdevila J, Estrada M, Sanchez-Herrero E, Guerrero I. The Drosophila segment polarity gene patched interacts with decapentaplegic in wing development. The EMBO journal. 1994a; 13:7182. [PubMed: 8306973]

Capdevila J, Pariente F, Sampedro J, Alonso JL, Guerrero I. Subcellular localization of the segment polarity protein patched suggests an interaction with the wingless reception complex in Drosophila embryos. Development. 1994b; 120:987-998. [PubMed: 7600973]

Chen CH, von Kessler DP, Park W, Wang B, Ma Y, Beachy PA. Nuclear trafficking of Cubitus interruptus in the transcriptional regulation of Hedgehog target gene expression. Cell. 1999; 98:305-316. [PubMed: 10458606]

Chen MH, Wilson CW, Li YJ, Law KK, Lu CS, Gacayan R, Zhang X, Hui CC, Chuang PT. Ciliumindependent regulation of Gli protein function by Sufu in Hedgehog signaling is evolutionarily conserved. Genes \& development. 2009; 23:1910-1928. [PubMed: 19684112]

Chen XL, Chinchilla P, Fombonne J, Ho L, Guix C, Keen JH, Mehlen P, Riobo NA. Patched-1 proapoptotic activity is downregulated by modification of $\mathrm{k} 1413$ by the e 3 ubiquitin-protein ligase itchy homolog. Molecular and cellular biology. 2014; 34:3855-3866. [PubMed: 25092867]

Chen Y, Sasai N, Ma G, Yue T, Jia J, Briscoe J, Jiang J. Sonic Hedgehog dependent phosphorylation by CK1 alpha and GRK2 is required for ciliary accumulation and activation of smoothened. PLoS biology. 2011a; 9:e1001083. [PubMed: 21695114] 
Chen Y, Struhl G. Dual roles for patched in sequestering and transducing Hedgehog. Cell. 1996; 87:553-563. [PubMed: 8898207]

Chen Y, Yue S, Xie L, Pu XH, Jin T, Cheng SY. Dual Phosphorylation of suppressor of fused (Sufu) by PKA and GSK3beta regulates its stability and localization in the primary cilium. The Journal of biological chemistry. 2011b; 286:13502-13511. [PubMed: 21317289]

Chen ZJ. Ubiquitination in signaling to and activation of IKK. Immunol Rev. 2012; 246:95-106. [PubMed: 22435549]

Cheng SY, Bishop JM. Suppressor of Fused represses Gli-mediated transcription by recruiting the SAP18-mSin3 corepressor complex. Proceedings of the National Academy of Sciences of the United States of America. 2002; 99:5442-5447. [PubMed: 11960000]

Chiang C, Litingtung Y, Lee E, Young KE, Corden JL, Westphal H, Beachy PA. Cyclopia and defective axial patterning in mice lacking Sonic hedgehog gene function. Nature. 1996; 383:407413. [PubMed: 8837770]

Cooper AF, Yu KP, Brueckner M, Brailey LL, Johnson L, McGrath JM, Bale AE. Cardiac and CNS defects in a mouse with targeted disruption of suppressor of fused. Development. 2005; 132:44074417. [PubMed: 16155214]

Corbit KC, Aanstad P, Singla V, Norman AR, Stainier DY, Reiter JF. Vertebrate Smoothened functions at the primary cilium. Nature. 2005; 437:1018-1021. [PubMed: 16136078]

Dai P, Akimaru H, Tanaka Y, Maekawa T, Nakafuku M, Ishii S. Sonic Hedgehog-induced activation of the Gli1 promoter is mediated by GLI3. The Journal of biological chemistry. 1999; 274:81438152. [PubMed: 10075717]

De Smaele E, Di Marcotullio L, Moretti M, Pelloni M, Occhione MA, Infante P, Cucchi D, Greco A, Pietrosanti L, Todorovic J, et al. Identification and characterization of KCASH2 and KCASH3, 2 novel Cullin3 adaptors suppressing histone deacetylase and Hedgehog activity in medulloblastoma. Neoplasia. 2011; 13:374-385. [PubMed: 21472142]

Denef N, Neubuser D, Perez L, Cohen SM. Hedgehog induces opposite changes in turnover and subcellular localization of patched and smoothened. Cell. 2000; 102:521-531. [PubMed: 10966113]

Deshaies RJ. SCF and Cullin/Ring H2-based ubiquitin ligases. Ann Rev Cell Dev Biol. 1999; 15:435467. [PubMed: 10611969]

Dessaud E, Yang LL, Hill K, Cox B, Ulloa F, Ribeiro A, Mynett A, Novitch BG, Briscoe J. Interpretation of the sonic hedgehog morphogen gradient by a temporal adaptation mechanism. Nature. 2007; 450:717-720. [PubMed: 18046410]

Di Marcotullio L, Ferretti E, Greco A, De Smaele E, Po A, Sico MA, Alimandi M, Giannini G, Maroder M, Screpanti I, et al. Numb is a suppressor of Hedgehog signalling and targets Gli1 for Itch-dependent ubiquitination. Nature cell biology. 2006; 8:1415-1423. [PubMed: 17115028]

Di Marcotullio L, Ferretti E, Greco A, De Smaele E, Screpanti I, Gulino A. Multiple ubiquitindependent processing pathways regulate hedgehog/gli signaling: implications for cell development and tumorigenesis. Cell Cycle. 2007; 6:390-393. [PubMed: 17312394]

Di Marcotullio L, Greco A, Mazza D, Canettieri G, Pietrosanti L, Infante P, Coni S, Moretti M, De Smaele E, Ferretti E, et al. Numb activates the E3 ligase Itch to control Gli1 function through a novel degradation signal. Oncogene. 2011; 30:65-76. [PubMed: 20818436]

Ding Q, Fukami S, Meng X, Nishizaki Y, Zhang X, Sasaki H, Dlugosz A, Nakafuku M, Hui CC. Mouse suppressor of fused is a negative regulator of sonic hedgehog signaling and alters the subcellular distribution of Gli1. Current biology : CB. 1999; 9:1119-1122. [PubMed: 10531011]

Ding Q, Motoyama J, Gasca S, Mo R, Sasaki H, Rossant J, Hui CC. Diminished Sonic hedgehog signaling and lack of floor plate differentiation in Gli2 mutant mice. Development. 1998; 125:2533-2543. [PubMed: 9636069]

Fan J, Jiang K, Liu Y, Jia J. Hrs promotes ubiquitination and mediates endosomal trafficking of smoothened in Drosophila hedgehog signaling. PloS one. 2013; 8:e79021. [PubMed: 24244405]

Fan J, Liu Y, Jia J. Hh-induced Smoothened conformational switch is mediated by differential phosphorylation at its C-terminal tail in a dose- and position-dependent manner. Developmental biology. 2012; 366:172-184. [PubMed: 22537496] 
Finley D. Recognition and processing of ubiquitin-protein conjugates by the proteasome. Annual review of biochemistry. 2009; 78:477-513.

Fombonne J, Bissey PA, Guix C, Sadoul R, Thibert C, Mehlen P. Patched dependence receptor triggers apoptosis through ubiquitination of caspase-9. Proceedings of the National Academy of Sciences of the United States of America. 2012; 109:10510-10515. [PubMed: 22679284]

Formstecher E, Aresta S, Collura V, Hamburger A, Meil A, Trehin A, Reverdy C, Betin V, Maire S, Brun C, et al. Protein interaction mapping: a Drosophila case study. Genome research. 2005; 15:376-384. [PubMed: 15710747]

Gilder AS, Chen YB, Jackson RJ 3rd, Jiang J, Maher JF. Fem1b promotes ubiquitylation and suppresses transcriptional activity of Gli1. Biochemical and biophysical research communications. 2013; 440:431-436. [PubMed: 24076122]

Goetz SC, Anderson KV. The primary cilium: a signalling centre during vertebrate development. Nature reviews Genetics. 2010; 11:331-344.

Goodrich LV, Johnson RL, Milenkovic L, McMahon JA, Scott MP. Conservation of the hedgehog/ patched signaling pathway from flies to mice: induction of a mouse patched gene by Hedgehog. Genes \& development. 1996; 10:301-312. [PubMed: 8595881]

Goodrich LV, Milenkovic L, Higgins KM, Scott MP. Altered neural cell fates and medulloblastoma in mouse patched mutants. Science. 1997; 277:1109-1113. [PubMed: 9262482]

Gradilla A, Guerrero I. Hedgehog on the move: a precise spatial control of Hedgehog dispersion shapes the gradient. Curr Opin Genet Dev. 2013:23. [PubMed: 24657533]

Guerrero I, Chiang C. A conserved mechanism of Hedgehog gradient formation by lipid modifications. Trends Cell Biol. 2007; 17:1-5. [PubMed: 17126548]

Gulino A, Di Marcotullio L, Canettieri G, De Smaele E, Screpanti I. Hedgehog/Gli control by ubiquitination/acetylation interplay. Vitamins and hormones. 2012; 88:211-227. [PubMed: 22391305]

Haglund K, Dikic I. Ubiquitylation and cell signaling. The EMBO journal. 2005; 24:3353-3359. [PubMed: 16148945]

Harfe BD, Scherz PJ, Nissim S, Tian H, McMahon AP, Tabin CJ. Evidence for an expansion-based temporal Shh gradient in specifying vertebrate digit identities. Cell. 2004; 118:517-528. [PubMed: 15315763]

Haycraft CJ, Banizs B, Aydin-Son Y, Zhang Q, Michaud EJ, Yoder BK. Gli2 and Gli3 localize to cilia and require the intraflagellar transport protein polaris for processing and function. PLoS Genetics. 2005; 1:e53. [PubMed: 16254602]

Hayer A, Stoeber M, Ritz D, Engel S, Meyer HH, Helenius A. Caveolin-1 is ubiquitinated and targeted to intralumenal vesicles in endolysosomes for degradation. The Journal of cell biology. 2010; 191:615-629. [PubMed: 21041450]

Hershko A, Ciechanover A. The ubiquitin system. Ann Rev Biochem. 1998; 67:425-479. [PubMed: 9759494]

Hu J, Wittekind SG, Barr MM. STAM and Hrs down-regulate ciliary TRP receptors. Molecular biology of the cell. 2007; 18:3277-3289. [PubMed: 17581863]

Huang K, Diener DR, Rosenbaum JL. The ubiquitin conjugation system is involved in the disassembly of cilia and flagella. The Journal of cell biology. 2009; 186:601-613. [PubMed: 19704024]

Huang S, Zhang Z, Zhang C, Lv X, Zheng X, Chen Z, Sun L, Wang H, Zhu Y, Zhang J, et al. Activation of Smurf E3 ligase promoted by smoothened regulates hedgehog signaling through targeting patched turnover. PLoS biology. 2013; 11:e1001721. [PubMed: 24302888]

Huangfu D, Anderson KV. Cilia and Hedgehog responsiveness in the mouse. Proceedings of the National Academy of Sciences of the United States of America. 2005; 102:11325-11330. [PubMed: 16061793]

Huangfu D, Anderson KV. Signaling from Smo to Ci/Gli: conservation and divergence of Hedgehog pathways from Drosophila to vertebrates. Development. 2006; 133:3-14. [PubMed: 16339192]

Hui CC, Angers S. Gli proteins in development and disease. Annual review of cell and developmental biology. 2011; 27:513-537.

Front Biol (Beijing). Author manuscript; available in PMC 2015 September 09. 
Humke EW, Dorn KV, Milenkovic L, Scott MP, Rohatgi R. The output of Hedgehog signaling is controlled by the dynamic association between Suppressor of Fused and the Gli proteins. Genes \& development. 2010; 24:670-682. [PubMed: 20360384]

Huntzicker EG, Estay IS, Zhen H, Lokteva LA, Jackson PK, Oro AE. Dual degradation signals control Gli protein stability and tumor formation. Genes \& development. 2006; 20:276-281. [PubMed: 16421275]

Ingham PW, Fietz MJ. Quantitative effects of hedgehog and decapentaplegic activity on the patterning of the Drosophila wing. Current biology : CB. 1995; 5:432-440. [PubMed: 7627558]

Ingham PW, Nakano Y, Seger C. Mechanisms and functions of Hedgehog signalling across the metazoa. Nature reviews Genetics. 2011; 12:393-406.

Izzi L, Levesque M, Morin S, Laniel D, Wilkes BC, Mille F, Krauss RS, McMahon AP, Allen BL, Charron F. Boc and Gas1 each form distinct Shh receptor complexes with Ptch1 and are required for Shh-mediated cell proliferation. Developmental cell. 2011; 20:788-801. [PubMed: 21664577]

Jackson PK, Eldridge AG, Freed E, Furstenthal L, Hsu JY, Kaiser BK, Reimann JDR. The lore of the RINGs: substrate recognition and catalysis by ubiquitin ligases. Trends Cell Biol. 2000; 10:429439. [PubMed: 10998601]

Jekely G, Rorth P. Hrs mediates downregulation of multiple signalling receptors in Drosophila. EMBO reports. 2003; 4:1163-1168. [PubMed: 14608370]

Jeong J, McMahon AP. Growth and pattern of the mammalian neural tube are governed by partially overlapping feedback activities of the hedgehog antagonists patched 1 and Hhip1. Development. 2005; 132:143-154. [PubMed: 15576403]

Jia J, Amanai K, Wang G, Tang J, Wang B, Jiang J. Shaggy/GSK3 antagonizes Hedgehog signalling by regulating Cubitus interruptus. Nature. 2002; 416:548-552. [PubMed: 11912487]

Jia J, Tong C, Wang B, Luo L, Jiang J. Hedgehog signalling activity of Smoothened requires phosphorylation by protein kinase A and casein kinase I. Nature. 2004; 432:1045-1050. [PubMed: 15616566]

Jia J, Zhang L, Zhang Q, Tong C, Wang B, Hou F, Amanai K, Jiang J. Phosphorylation by doubletime/CKIepsilon and CKIalpha targets cubitus interruptus for Slimb/beta-TRCP-mediated proteolytic processing. Developmental cell. 2005; 9:819-830. [PubMed: 16326393]

Jiang J. Regulation of Hh/Gli signaling by dual ubiquitin pathways. Cell Cycle. 2006; 5:2457-2463. [PubMed: 17102630]

Jiang J, Hui CC. Hedgehog signaling in development and cancer. Developmental cell. 2008; 15:801812. [PubMed: 19081070]

Kawamura S, Hervold K, Ramirez-Weber FA, Kornberg TB. Two patched protein subtypes and a conserved domain of group I proteins that regulates turnover. The Journal of biological chemistry. 2008; 283:30964-30969. [PubMed: 18768465]

Kent D, Bush EW, Hooper JE. Roadkill attenuates Hedgehog responses through degradation of Cubitus interruptus. Development. 2006; 133:2001-2010. [PubMed: 16651542]

Kim J, Kato M, Beachy PA. Gli2 trafficking links Hedgehog-dependent activation of Smoothened in the primary cilium to transcriptional activation in the nucleus. Proceedings of the National Academy of Sciences of the United States of America. 2009; 106:21666-21671. [PubMed: 19996169]

Kise Y, Morinaka A, Teglund S, Miki H. Sufu recruits GSK3beta for efficient processing of Gli3. Biochemical and biophysical research communications. 2009; 387:569-574. [PubMed: 19622347]

Kogerman P, Grimm T, Kogerman L, Krause D, Unden A, Sandstedt B, Toftgard R, Zaphiropoulos PG. Mammalian Suppressor-of-Fused modulates nuclear-cytoplasmic shuttling of GLI-1. Nature cell biology. 1999; 1:312-319. [PubMed: 10559945]

Koudjis MJ, den Broeder MJ, Keijser A, Wienholds E, Houwing S, van Rooijen EM, Geisler R, van Eeden FJ. The zebrafish mutants dre, uki, and lep encode negative regulators of the hedgehog signaling pathway. PLoS Genetics. 2005; 1:E19. [PubMed: 16121254]

Kovacs JJ, Whalen EJ, Liu R, Xiao K, Kim J, Chen M, Wang J, Chen W, Lefkowitz RJ. Beta-arrestinmediated localization of smoothened to the primary cilium. Science. 2008; 320:1777-1781. [PubMed: 18497258] 
Lee JD, Amanai K, Shearn A, Treisman JE. The ubiquitin ligase Hyperplastic discs negatively regulates hedgehog and decapentaplegic expression by independent mechanisms. Development. 2002; 129:5697-5706. [PubMed: 12421709]

Lee TA, Tyers M. Ubiquitin junction, what's your function? Genome Biol. 2001; 2 REPORTS4025.

Li S, Chen Y, Shi Q, Yue T, Wang B, Jiang J. Hedgehog-regulated ubiquitination controls smoothened trafficking and cell surface expression in Drosophila. PLoS biology. 2012; 10:e1001239. [PubMed: 22253574]

Liu A, Wang B, Niswander LA. Mouse intraflagellar transport proteins regulate both the activator and repressor functions of Gli transcription factors. Development. 2005; 132:3103-3111. [PubMed: 15930098]

Liu C, Zhou Z, Yao X, Chen P, Sun M, Su M, Chang C, Yan J, Jiang J, Zhang Q. Hedgehog signaling downregulates suppressor of fused through the HIB/SPOP-Crn axis in Drosophila. Cell research. 2014a; 24:595-609. [PubMed: 24603360]

Liu Z, Li T, Reinhold MI, Naski MC. MEK1-RSK2 contributes to Hedgehog signaling by stabilizing GLI2 transcription factor and inhibiting ubiquitination. Oncogene. 2014b; 33:65-73. [PubMed: 23208494]

Lu X, Liu S, Kornberg TB. The C-terminal tail of the Hedgehog receptor Patched regulates both localization and turnover. Genes \& development. 2006; 20:2539-2551. [PubMed: 16980583]

Lum L, Beachy PA. The Hedgehog response network: sensors, switches, and routers. Science. 2004; 304:1755-1759. [PubMed: 15205520]

Marigo V, Davey RA, Zuo Y, Cunningham JM, Tabin CJ. Biochemical evidence that patched is the Hedgehog receptor. Nature. 1996; 384:176-179. [PubMed: 8906794]

Matise MP, Epstein DJ, Park HL, Platt KA, Joyner AL. Gli2 is required for induction of floor plate and adjacent cells, but not most ventral neurons in the mouse central nervous system. Development. 1998; 125:2759-2770. [PubMed: 9655799]

May SR, Ashique AM, Karlen M, Wang B, Shen Y, Zarbalis K, Reiter J, Ericson J, Peterson AS. Loss of the retrograde motor for IFT disrupts localization of Smo to cilia and prevents the expression of both activator and repressor functions of Gli. Developmental biology. 2005; 287:378-389. [PubMed: 16229832]

Mazumdar T, DeVecchio J, Shi T, Jones J, Agyeman A, Houghton JA. Hedgehog signaling drives cellular survival in human colon carcinoma cells. Cancer research. 2011; 71:1092-1102. [PubMed: 21135115]

Mazza D, Infante P, Colicchia V, Greco A, Alfonsi R, Siler M, Antonucci L, Po A, De Smaele E, Ferretti E, et al. PCAF ubiquitin ligase activity inhibits Hedgehog/Gli1 signaling in p53-dependent response to genotoxic stress. Cell death and differentiation. 2013; 20:1688-1697. [PubMed: 24013724]

McDermott A, Gustafsson M, Elsam T, Hui CC, Emerson CP Jr, Borycki AG. Gli2 and Gli3 have redundant and context-dependent function in skeletal muscle formation. Development. 2005; 132:345-357. [PubMed: 15604102]

McGlinn E, Tabin CJ. Mechanistic insight into how Shh patterns the vertebrate limb. Curr Opin Genet Dev. 2006:426-432. [PubMed: 16806898]

McLellan JS, Yao S, Zheng X, Geisbrecht BV, Ghirlando R, Beachy PA, Leahy DJ. Structure of a heparin-dependent complex of Hedgehog and Ihog. Proceedings of the National Academy of Sciences of the United States of America. 2006; 103:17208-17213. [PubMed: 17077139]

Methot N, Basler K. Hedgehog controls limb development by regulating the activities of distinct transcriptional activator and repressor forms of Cubitus interruptus. Cell. 1999; 96:819-831. [PubMed: 10102270]

Methot N, Basler K. Suppressor of fused opposes hedgehog signal transduction by impeding nuclear accumulation of the activator form of Cubitus interruptus. Development. 2000; 127:4001-4010. [PubMed: 10952898]

Mille F, Thibert C, Fombonne J, Rama N, Guix C, Hayashi H, Corset V, Reed JC, Mehlen P. The Patched dependence receptor triggers apoptosis through a DRAL-caspase-9 complex. Nature cell biology. 2009; 11:739-746. [PubMed: 19465923] 
Monnier V, Dussillol F, Alves G, Lamour-Isnard C, Plessis A. Suppressor of fused links fused and Cubitus interruptus on the hedgehog signalling pathway. Current biology : CB. 1998; 7:583-586. [PubMed: 9601642]

Motoyama J, Milenkovic L, Iwama M, Shikata Y, Scott MP, Hui CC. Differential requirement for Gli2 and Gli3 in ventral neural cell fate specification. Developmental biology. 2003:150-161. [PubMed: 12812795]

Nachury MV, Seeley ES, Jin H. Trafficking to the ciliary membrane: how to get across the periciliary diffusion barrier? Annual review of cell and developmental biology. 2010; 26:59-87.

Nakano Y, Nystedt S, Shivdasani AA, Strutt H, Thomas C, Ingham PW. Functional domains and subcellular distribution of the Hedgehog transducing protein Smoothened in Drosophila. Mechanisms of development. 2004; 121:507-518. [PubMed: 15172682]

Nieuwenhuis E, Hui CC. Hedgehog signaling and congenital malformations. Clinical genetics. 2005; 67:193-208. [PubMed: 15691355]

Nieuwenhuis E, Motoyama J, Barnfield PC, Yoshikawa Y, Zhang X, Mo R, Crackower MA, Hui CC. Mice with a targeted mutation of patched 2 are viable but develop alopecia and epidermal hyperplasia. Molecular and cellular biology. 2006; 26:6609-6622. [PubMed: 16914743]

Ohlmeyer J, Kalderon D. Hedgehog stimulates maturation of Cubitus interruptus into a labile transcriptional activator. Nature. 1998; 396:749-753. [PubMed: 9874371]

Okada A, Charron F, Morin S, Shin DS, Wong K, Fabre PJ, Tessier-Lavigne M, McConnell SK. Boc is a receptor for sonic hedgehog in the guidance of commissural axons. Nature. 2006; 444:369373. [PubMed: 17086203]

Oshiumi H, Matsumoto M, Seya T. Ubiquitin-mediated modulation of the cytoplasmic viral RNA sensor RIG-I. Journal of biochemistry. 2012; 151:5-11. [PubMed: 21890623]

Ou CY, Wang CH, Jiang J, Chien CT. Suppression of Hedgehog signaling by Cul3 ligases in proliferation control of retinal precursors. Developmental biology. 2007; 308:106-119. [PubMed: 17559828]

Paces-Fessy M, Boucher D, Petit E, Paute-Briand S, Blanchet-Tournier MF. The negative regulator of Gli, Suppressor of fused (Sufu), interacts with SAP18, Galectin3 and other nuclear proteins. The Biochemical journal. 2004; 378:353-362. [PubMed: 14611647]

Pan Y, Wang C, Wang B. Phosphorylation of Gli2 by protein kinase A is required for Gli2 processing and degradation and the Sonic Hedgehog-regulated mouse development. Developmental biology. 2009; 326:177-189. [PubMed: 19056373]

Park HL, Bai C, Platt KA, Matise MP, Beeghly A, Hui CC, Nakashima M, Joyner AL. Mouse Gli1 mutants are viable but have defects in SHH signaling in combination with a Gli2 mutation. Development. 2000; 127:1593-1605. [PubMed: 10725236]

Persson M, Stamataki D, te Welscher P, Andersson E, Bose J, Ruther U, Ericson J, Briscoe J. Dorsalventral patterning of the spinal cord requires Gli3 transcriptional repressor activity. Genes \& development. 2002; 16:2865-2878. [PubMed: 12435629]

Petrova R, Joyner AL. Roles for Hedgehog signaling in adult organ homeostasis and repair. Development. 2014; 141:3445-3457. [PubMed: 25183867]

Pickart CM. Mechanisms underlying ubiquitination. Annual review of biochemistry. 2001; 70:503533.

Pickart CM. Back to the future with ubiquitin. Cell. 2004; 116:181-190. [PubMed: 14744430]

Pickart CM, Eddins MJ. Ubiquitin: structures, functions, mechanisms. Biochimica et biophysica acta. 2004; 1695:55-72. [PubMed: 15571809]

Polo S, Di Fiore PP. Endocytosis conducts the cell signaling orchestra. Cell. 2006; 124:897-900. [PubMed: 16530038]

Preat T. Characterization of Suppressor of fused, a Complete Suppressor of the fused Segment Polarity Gene of Drosophila melanogaster. Genetics. 1992; 132:725-736. [PubMed: 1468628]

Price MA, Kalderon D. Proteolysis of the Hedgehog signaling effector Cubitus interruptus requires phosphorylation by Glycogen Synthase Kinase 3 and Casein Kinase 1. Cell. 2002; 108:823-835. [PubMed: 11955435] 
Quirin K, Eschli B, Scheu I, Poort L, Kartenbeck J, Helenius A. Lymphocytic choriomeningitis virus uses a novel endocytic pathway for infectious entry via late endosomes. Virology. 2008; 378:2133. [PubMed: 18554681]

Rohatgi R, Milenkovic L, Corcoran RB, Scott MP. Hedgehog signal transduction by Smoothened: pharmacologic evidence for a 2-step activation process. Proceedings of the National Academy of Sciences of the United States of America. 2009; 106:3196-3201. [PubMed: 19218434]

Rohatgi R, Milenkovic L, Scott MP. Patched1 regulates hedgehog signaling at the primary cilium. Science. 2007; 317:372-376. [PubMed: 17641202]

Rohatgi R, Scott MP. Patching the gaps in Hedgehog signalling. Nature cell biology. 2007; 9:10051009. [PubMed: 17762891]

Sandvig K, Pust S, Skotland T, van Deurs B. Clathrin-independent endocytosis: mechanisms and function. Curr Opin Cell Biol. 2011; 23:413-420. [PubMed: 21466956]

Santos N, Reiter JF. A central region of Gli2 regulates its localization to the primary cilium and transcriptional activity. Journal of cell science. 2014; 127:1500-1510. [PubMed: 24463817]

Sasaki H, Nishizaki Y, Hui CC, Nakafuku M, Kondoh H. Regulation of Gli2 and Gli3 activities by an amino-terminal repression domain: implication of Gli2 and Gli3 as primary mediators of Shh signaling. Development. 1999; 126:3915-3924. [PubMed: 10433919]

Scherz PJ, McGlinn E, Nissim S, Tabin CJ. Extended exposure to Sonic hedgehog is required for patterning the posterior digits of the vertebrate limb. Developmental biology. 2007; 308:343354. [PubMed: 17610861]

Sigismund S, Polo S, Di Fiore PP. Signaling through monoubiquitination. Curr Top Microbiol Immunol. 2004:286.

Smelkinson MG, Kalderon D. Processing of the Drosophila hedgehog signaling effector Ci-155 to the repressor Ci-75 is mediated by direct binding to the SCF component Slimb. Current biology : CB. 2006; 16:110-116. [PubMed: 16386907]

St-Jacques B, Hammerschmidt M, McMahon AP. Indian hedgehog signaling regulates proliferation and differentiation of chondrocytes and is essential for bone formation. Genes \& development. 1999; 13:2072-2086. [PubMed: 10465785]

Stamataki D, Ulloa F, Tsoni SV, Mynett A, Briscoe J. A gradient of Gli activity mediates graded Sonic Hedgehog signaling in the neural tube. Genes \& development. 2005; 19:626-641. [PubMed: 15741323]

Svard J, Heby-Henricson K, Persson-Lek M, Rozell B, Lauth M, Bergstrom A, Ericson J, Toftgard R, Teglund S. Genetic elimination of Suppressor of fused reveals an essential repressor function in the mammalian Hedgehog signaling pathway. Developmental cell. 2006; 10:187-197. [PubMed: 16459298]

Tabata T, Kornberg TB. Hedgehog is a signaling protein with a key role in patterning Drosophila imaginal discs. Cell. 1994; 76:89-102. [PubMed: 8287482]

Taipale J, Beachy P. The Hedgehog and Wnt signalling pathways in cancer. Nature. 2001; 411:349_ 354. [PubMed: 11357142]

Teglund S, Toftgard R. Hedgehog beyond medulloblastoma and basal cell carcinoma. Biochimica et biophysica acta. 2010; 1805:181-208. [PubMed: 20085802]

Tempe D, Casas M, Karaz S, Blanchet-Tournier MF, Concordet JP. Multisite protein kinase A and glycogen synthase kinase 3beta phosphorylation leads to Gli3 ubiquitination by SCFbetaTrCP. Molecular and cellular biology. 2006; 26:4316-4326. [PubMed: 16705181]

Tenzen T, Allen BL, Cole F, Kang JS, Krauss RS, McMahon AP. The cell surface membrane proteins Cdo and Boc are components and targets of the Hedgehog signaling pathway and feedback network in mice. Developmental cell. 2006; 10:647-656. [PubMed: 16647304]

Thibert C, Teillet MA, Lapointe F, Mazelin L, Le Douarin NM, Mehlen P. Inhibition of neuroepithelial patched-induced apoptosis by sonic hedgehog. Science. 2003; 301:843-846. [PubMed: 12907805]

Torroja C, Gorfinkiel N, Guerrero I. Patched controls the Hedgehog gradient by endocytosis in a dynamin-dependent manner, but this internalization does not play a major role in signal transduction. Development. 2004; 131:2395-2408. [PubMed: 15102702] 
Torroja C, Gorfinkiel N, Guerrero I. Mechanisms of Hedgehog gradient formation and interpretation. Journal of neurobiology. 2005; 64:334-356. [PubMed: 16041759]

Tukachinsky H, Lopez LV, Salic A. A mechanism for vertebrate Hedgehog signaling: recruitment to cilia and dissociation of SuFu-Gli protein complexes. The Journal of cell biology. 2010; 191:415-428. [PubMed: 20956384]

Varjosalo M, Bjorklund M, Cheng F, Syvanen H, Kivioja T, Kilpinen S, Sun Z, Kallioniemi O, Stunnenberg HG, He WW, et al. Application of active and kinase-deficient kinome collection for identification of kinases regulating hedgehog signaling. Cell. 2008; 133:537-548. [PubMed: 18455992]

Varjosalo M, Taipale J. Hedgehog: functions and mechanisms. Genes \& development. 2008; 22:24542472. [PubMed: 18794343]

Verma R, Deshaies RJ. A proteasome howdunit: the case of the missing signal. Cell. 2000; 101:341344. [PubMed: 10830160]

Voges D, Zwickl P, Baumeister W. The 26S proteasome: a molecular machine designed for controlled proteolysis. Ann Rev Biochem. 1999; 68:1015-1068. [PubMed: 10872471]

Wang B, Fallon JF, Beachy PA. Hedgehog-Regulated Processing of Gli3 Produces an Anterior/ Posterior Repressor Gradient in the Developing Vertebrate Limb. Cell. 2000a; 100:423-434. [PubMed: 10693759]

Wang B, Li Y. Evidence for the direct involvement of \{beta $\}$ TrCP in Gli3 protein processing. Proceedings of the National Academy of Sciences of the United States of America. 2006; 103:33-38. [PubMed: 16371461]

Wang C, Pan Y, Wang B. Suppressor of fused and Spop regulate the stability, processing and function of Gli2 and Gli3 full-length activators but not their repressors. Development. 2010; 137:20012009. [PubMed: 20463034]

Wang G, Amanai K, Wang B, Jiang J. Interactions with Costal2 and suppressor of fused regulate nuclear translocation and activity of cubitus interruptus. Genes \& development. 2000b; 14:28932905. [PubMed: 11090136]

Wang G, Tang X, Chen Y, Cao J, Huang Q, Ling X, Ren W, Liu S, Wu Y, Ray L, et al. Hyperplastic discs differentially regulates the transcriptional outputs of hedgehog signaling. Mechanisms of development. 2014

Wang G, Wang B, Jiang J. Protein kinase A antagonizes Hedgehog signaling by regulating both the activator and repressor forms of Cubitus interruptus. Genes \& development. 1999; 13:28282837. [PubMed: 10557210]

Wang QT, Holmgren RA. The subcellular localization and activity of Drosophila cubitus interruptus are regulated at multiple levels. Development. 1999; 126:5097-5106. [PubMed: 10529426]

Wang Y, Zhou Z, Walsh CT, McMahon AP. Selective translocation of intracellular Smoothened to the primary cilium in response to Hedgehog pathway modulation. Proceedings of the National Academy of Sciences of the United States of America. 2009; 106:2623-2628. [PubMed: 19196978]

Weissman AM. Themes and variations on ubiquitylation. Nature reviews Molecular cell biology. 2001; 2:169-178. [PubMed: 11265246]

Wen X, Lai CK, Evangelista M, Hongo JA, de Sauvage FJ, Scales SJ. Kinetics of hedgehog-dependent full-length Gli3 accumulation in primary cilia and subsequent degradation. Molecular and cellular biology. 2010; 30:1910-1922. [PubMed: 20154143]

Williams RL, Urbe S. The emerging shape of the ESCRT machinery. Nature reviews Molecular cell biology. 2007; 8:355-368. [PubMed: 17450176]

Wilson CW, Chen MH, Chuang PT. Smoothened adopts multiple active and inactive conformations capable of trafficking to the primary cilium. PloS one. 2009; 4:e5182. [PubMed: 19365551]

Woelk T, Sigismund S, Penengo L, Polo S. The ubiquitination code: a signalling problem. Cell Div. 2007; 2:11. [PubMed: 17355622]

Wolff C, Roy S, Ingham PW. Multiple muscle cell identities induced by distinct levels and timing of hedgehog activity in the zebrafish embryo. Current biology?: CB. 2003; 13:1169-1181. [PubMed: 12867027] 
Xia R, Jia H, Fan J, Liu Y, Jia J. USP8 promotes smoothened signaling by preventing its ubiquitination and changing its subcellular localization. PLoS biology. 2012; 10:e1001238. [PubMed: 22253573]

Xu P, Duong DM, Seyfried NT, Cheng D, Xie Y, Robert J, Rush J, Hochstrasser M, Finley D, Peng J. Quantitative proteomics reveals the function of unconventional ubiquitin chains in proteasomal degradation. Cell. 2009; 137:133-145. [PubMed: 19345192]

Yang X, Mao F, Lv X, Zhang Z, Fu L, Lu Y, Wu W, Zhou Z, Zhang L, Zhao Y. Drosophila Vps36 regulates Smo trafficking in Hedgehog signaling. Journal of cell science. 2013; 126:4230-4238. [PubMed: 23843610]

Yao S, Lum L, Beachy P. The ihog cell-surface proteins bind Hedgehog and mediate pathway activation. Cell. 2006; 125:343-357. [PubMed: 16630821]

Yue S, Chen Y, Cheng SY. Hedgehog signaling promotes the degradation of tumor suppressor Sufu through the ubiquitin-proteasome pathway. Oncogene. 2009; 28:492-499. [PubMed: 18997815]

Yue S, Tang LY, Tang Y, Tang Y, Shen QH, Ding J, Chen Y, Zhang Z, Yu TT, Zhang YE, et al. Requirement of Smurf-mediated endocytosis of Patched1 in Sonic Hedgehog signal reception. eLife. 2014:e02555.

Zeng H, Jia J, Liu A. Coordinated translocation of mammalian Gli proteins and suppressor of fused to the primary cilium. PloS one. 2010; 5:e15900. [PubMed: 21209912]

Zhang C, Williams EH, Guo Y, Lum L, Beachy PA. Extensive phosphorylation of Smoothened in Hedgehog pathway activation. Proceedings of the National Academy of Sciences of the United States of America. 2004; 101:17900-17907. [PubMed: 15598741]

Zhang Q, Zhang L, Wang B, Ou CY, Chien CT, Jiang J. A hedgehog-induced BTB protein modulates hedgehog signaling by degrading Ci/Gli transcription factor. Developmental cell. 2006a; 10:719729. [PubMed: 16740475]

Zhang W, Kang JS, Cole F, Yi MJ, Krauss RS. Cdo functions at multiple points in the Sonic Hedgehog pathway, and Cdo-deficient mice accurately model human holoprosencephaly. Developmental cell. 2006b; 10:657-665. [PubMed: 16647303]

Zhang W, Zhao Y, Tong C, Wang G, Wang B, Jia J, Jiang J. Hedgehog-regulated Costal2-kinase complexes control phosphorylation and proteolytic processing of Cubitus interruptus. Developmental cell. 2005; 8:267-278. [PubMed: 15691767]

Zhang XM, Ramalho-Santos M, McMahon AP. Smoothened mutants reveal redundant roles for Shh and Ihh signaling including regulation of L/R symmetry by the mouse node. Cell. 2001; 106:781-792. [PubMed: 11517919]

Zhang Z, Lv X, Yin WC, Zhang X, Feng J, Wu W, Hui CC, Zhang L, Zhao Y. Ter94 ATPase complex targets k11-linked ubiquitinated ci to proteasomes for partial degradation. Developmental cell. 2013; 25:636-644. [PubMed: 23747190]

Zhao Y, Tong C, Jiang J. Hedgehog regulates smoothened activity by inducing a conformational switch. Nature. 2007; 450:252-258. [PubMed: 17960137]

Zheng X, Mann RK, Sever N, Beachy PA. Genetic and biochemical definition of the Hedgehog receptor. Genes \& development. 2010; 24:57-71. [PubMed: 20048000]

Zhu AJ, Zheng L, Suyama K, Scott MP. Altered localization of Drosophila Smoothened protein activates Hedgehog signal transduction. Genes \& development. 2003; 17:1240-1252. [PubMed: 12730121] 

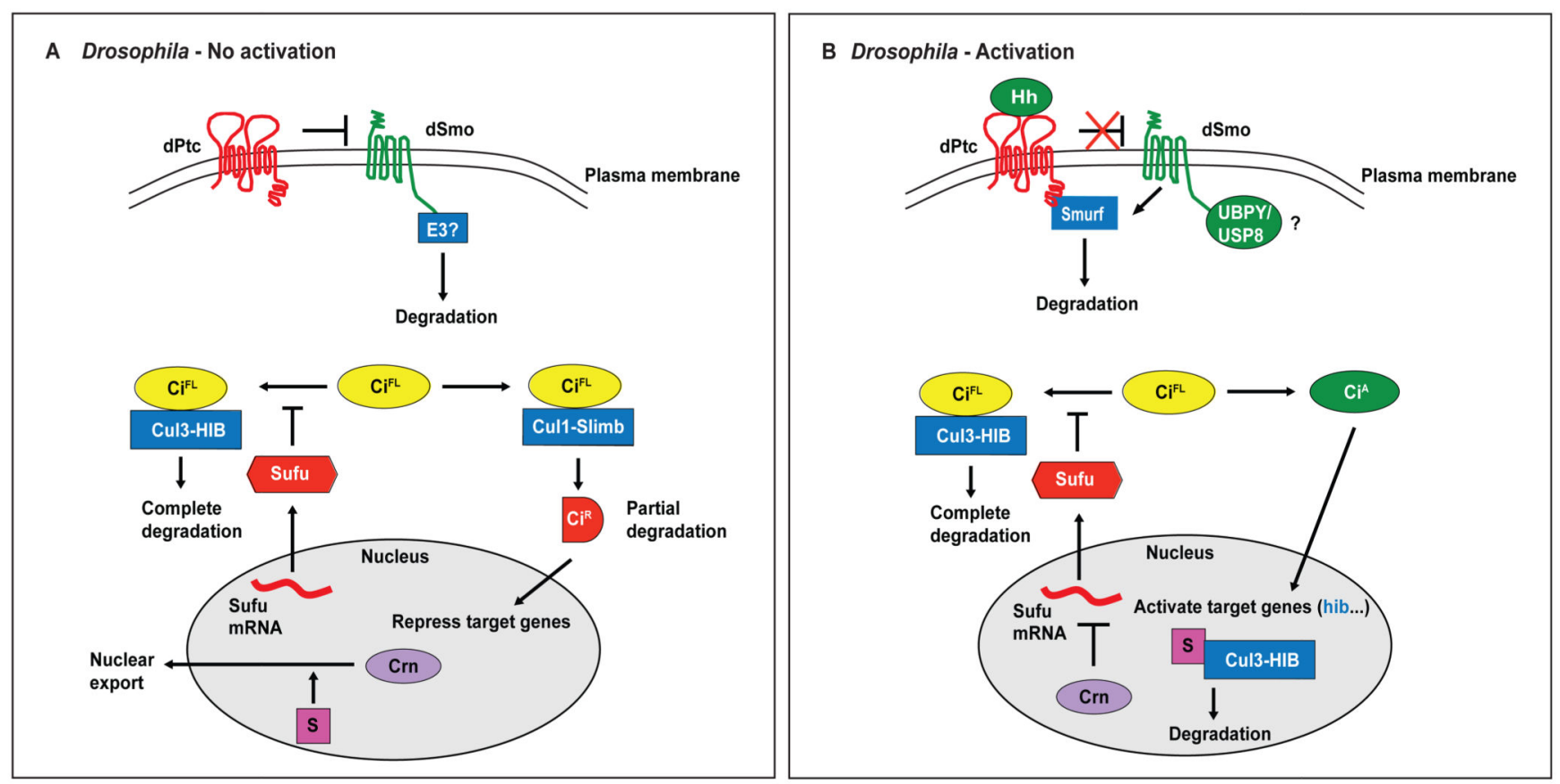

C Vertebrates - No activation
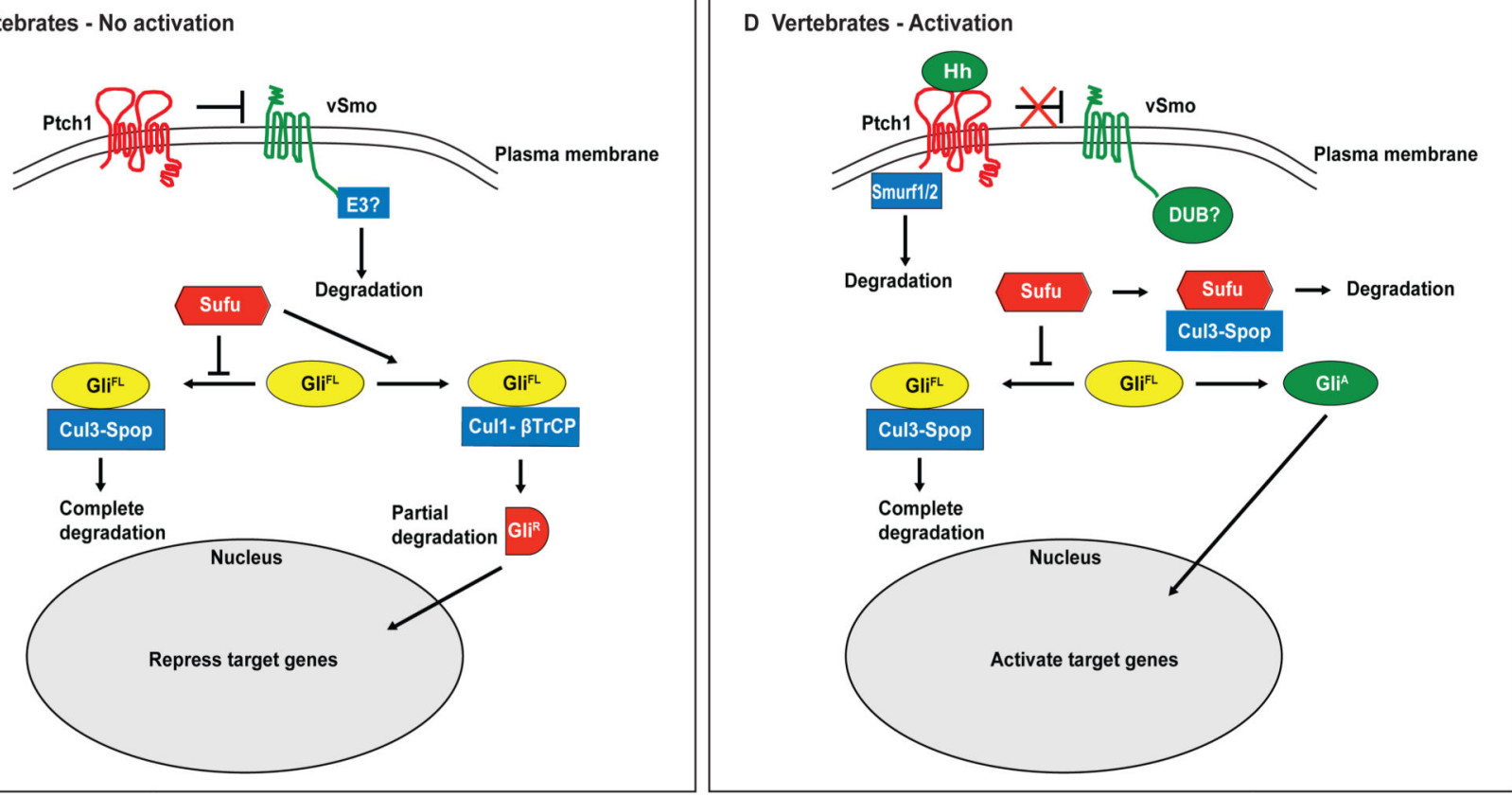

Figure 1. Regulation of Hedgehog signaling by ubiquitination

(A) In Drosophila, dPtc localized at the plasma membrane suppresses dSmo activity in the absence of Hh. An unknown E3 ligase (E3?) promotes internalization and degradation of dSmo. Sufu sequesters full-length $\mathrm{Ci}\left(\mathrm{Ci}^{\mathrm{FL}}\right)$ in the cytoplasm and protects $\mathrm{Ci}^{\mathrm{FL}}$ from spurious Cul3-HIB-mediated degradation. $\mathrm{Ci}^{\mathrm{FL}}$ is also targeted by Cul1-Slimb for partial degradation to the repressor form $\mathrm{Ci}^{\mathrm{R}}$ leading to repression of pathway target genes. Nuclear export of the spliceosome factor Crn by an unknown substrate (S) allows functional Sufu mRNA to be translated. $(B)$ Hh binding to dPtc releases its inhibition on dSmo. UBPY/ 
USP8 reverses dSmo ubiquitination and promotes dSmo accumulation at the plasma membrane, although this can also occur in the absence of Hh. Activated dSmo recruits Smurf to the plasma membrane where Smurf mediates the internalization and degradation of dPtc. Cul1-Slimb-mediated $\mathrm{Ci}^{\mathrm{R}}$ formation is inhibited, allowing for formation of the activator form $\mathrm{Ci}^{\mathrm{A}}$ and activation of pathway target genes including hib. HIB functions in a negative feedback manner by promoting the degradation of $\mathrm{Ci}^{\mathrm{FL}}$. Cul3-HIB also targets the unknown substrate $\mathrm{S}$ for degradation, allowing $\mathrm{Crn}$ to accumulate in the nucleus where it inhibits formation of functional Sufu mRNA and leads to reduced Sufu protein synthesis. (C) In vertebrates, in the absence of Hh ligands, Ptch1 suppresses activation of vSmo, which is internalized and degraded by an unknown E3 ligase. Sufu protects full-length Gli2 and $\mathrm{Gli3}\left(\mathrm{Gli}^{\mathrm{FL}}\right)$ from Cul3-Spop-mediated degradation. Sufu also promotes the partial degradation of $\mathrm{Gli}^{\mathrm{FL}}$ to $\mathrm{Gli}^{\mathrm{R}}$ by $\mathrm{Cul1}-\beta \operatorname{TrCP}$. $(D)$ In the presence of Hh ligands, Ptch1 is internalized and degraded by Smurf1/2. An unknown deubiquitinase (DUB) decreases vSmo ubiquitination and degradation. Sufu is degraded in a Cul3-Spop-dependent manner, and $\mathrm{Gli}^{\mathrm{R}}$ formation by $\mathrm{Cul1}-\beta \mathrm{TrCP}$ is inhibited, allowing for $\mathrm{Gli}^{\mathrm{A}}$ formation. 


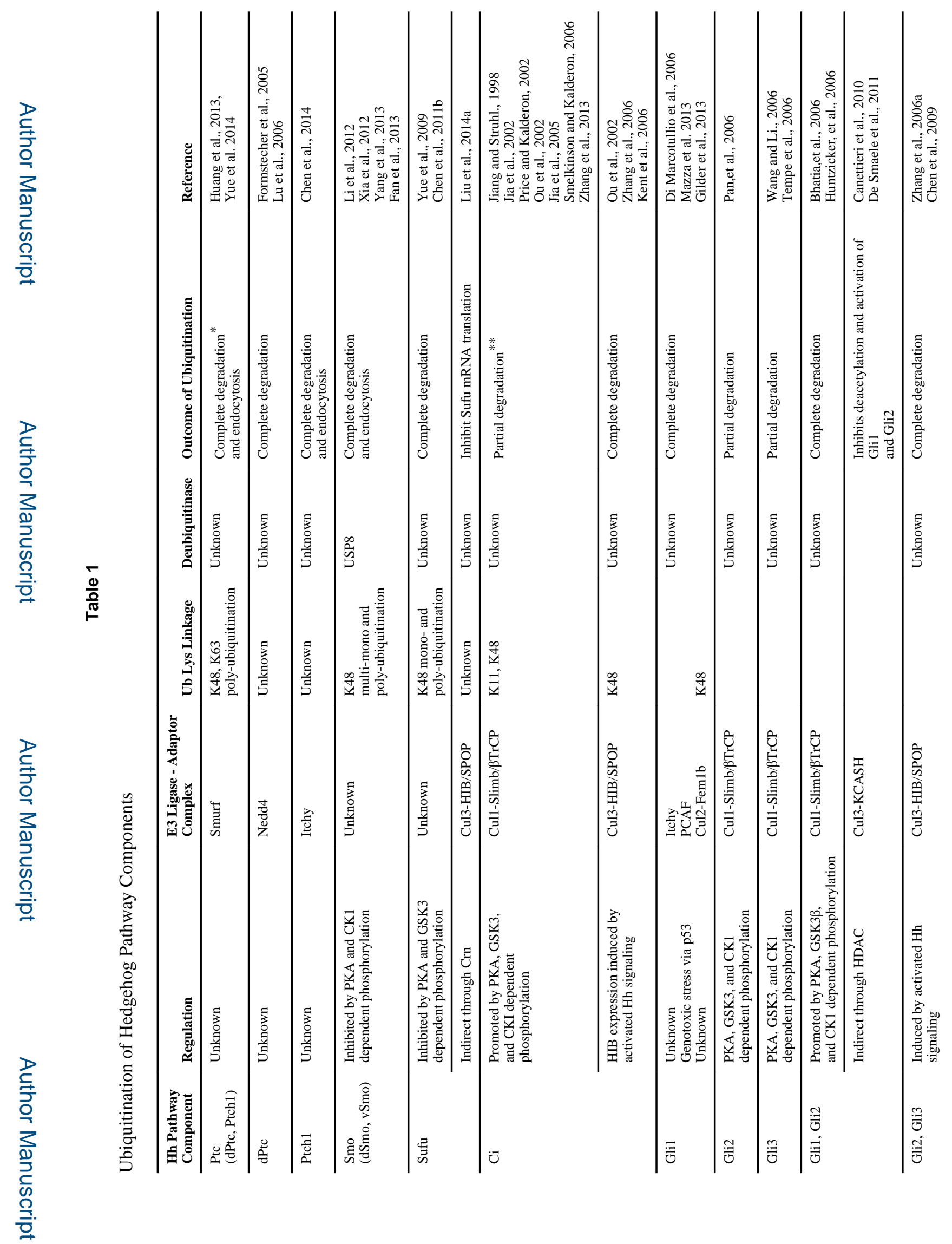

Front Biol (Beijing). Author manuscript; available in PMC 2015 September 09. 


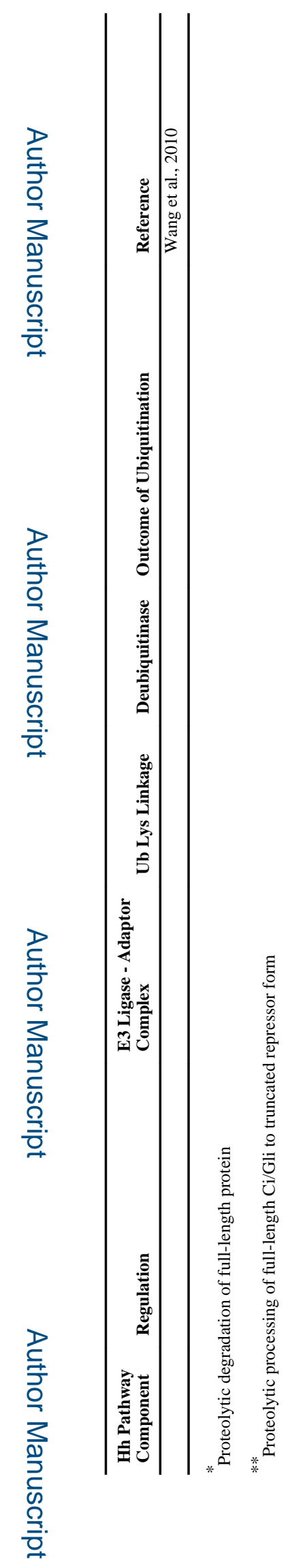

